\title{
Incidence, mortality and survival in children and young people aged 11-25 in Wales with co-occurring mental disorders and problem, hazardous or harmful substance use: estimates derived from linked routine data
}

Sarah Rees ( $\nabla$ s.e.r.rees@swansea.ac.uk)

Swansea University Medical School https://orcid.org/0000-0002-1939-0120

Alan Watkins

Swansea University Medical School

Janet Keauffling

Abertawe Medical Partnership

Ann John

Swansea University Medical School

\section{Research article}

Keywords: Mental disorder, substance use disorder, co-occurring conditions, dual diagnosis, routine data linkage, mental health of children and young people, Wales, incidence, mortality, survival.

Posted Date: August 3rd, 2020

DOI: https://doi.org/10.21203/rs.3.rs-50077/v1

License: (a) (i) This work is licensed under a Creative Commons Attribution 4.0 International License. Read Full License

Version of Record: A version of this preprint was published at Clinical Epidemiology on January 13th, 2022. See the published version at https://doi.org/10.2147/CLEP.S325235. 


\section{Abstract}

Background Mental disorder (MD) and problem, hazardous or harmful substance use (SUD) are associated with poorer than average health and greater mortality. We analysed routine data to estimate incidence of co-occurring (CC) MD and SUD, and to estimate all-cause mortality and survival with CC, a single MD or SUD diagnosis or neither condition (NC), in young people aged 11-25 in Wales, UK.

Methods A retrospective population-based electronic cohort study using data from the Secure Anonymised Information Linkage (SAIL) Databank. Participants were 958,603 individuals aged 11-25 between 2008 and 2017, with a subset for mortality and survival analysis of 465,242 individuals born between 1983 and 1997 and present in the data on $1^{\text {st }}$ January 2008.

Incidence was defined as date of first recorded occurrence of a CC code. Incidence and observed unadjusted mortality were reported as rates per 1,000 personyears at risk (PYAR). We plotted Kaplan-Meier survival curves and carried out Cox regression to estimate hazard ratios for risk of death by condition group (CC; MD or SUD only; NC).

Results CC incidence in primary care significantly decreased, from 2.5/1,000 PYAR (95\% Cl 2.3-2.6) in 2008 to 2.1/1,000 (95\% Cl 2.0-2.2) in 2017 (Incidence rate ratio $(\mathrm{IRR})=0.9,95 \% \mathrm{Cl} 0.8-1.0, \mathrm{p}=0.01)$, and in hospital admissions remained stable, from 2.3/1,000 (95\% Cl 2.1-2.4) in 2008 to $2.2 / 1,000$ (95\% $\mathrm{Cl} 2.0$ 2.3 ) in 2017 (IRR $=1.0,95 \% \mathrm{Cl}$ 0.9-1.1). Higher incidence was associated with male sex, older age and greater deprivation.

Observed unadjusted mortality rates for CC (1.4/1,000 PYAR, 95\% Cl 1.2-1.5) and SUD only $(1.1 / 1,000,95 \% \mathrm{Cl} 0.9-1.4)$ were significantly higher than for MD only $(0.4 / 1,000,95 \% \mathrm{Cl} 0.3-0.4)$ and no condition (NC) $(0.3 / 1,000,95 \% \mathrm{Cl} 0.2-0.3)$. Risk of death was significantly higher for CC (HR $=8.7,95 \% \mathrm{Cl} 7.5-10.0$, $\mathrm{p}<0.001)$, SUD only $(\mathrm{HR}=4.5,95 \% \mathrm{Cl} 3.4-5.9, \mathrm{p}<0.001)$ and $\mathrm{MD}$ only $(\mathrm{HR}=2.7,95 \% \mathrm{Cl} 2.4-3.1, \mathrm{p}<0.001)$, compared with NC.

Conclusions Male sex, older age and greater deprivation were associated with significantly higher CC incidence. CC, and also SUD or MD only, were associated with greater risk of death, compared with individuals with NC.

\section{Background}

Mental disorders (MD) and problem, hazardous or harmful drug or alcohol use (SUD) together account for $7.4 \%$ of the global burden of disease and are the leading causes of years lived with disability (YLD) (1). They frequently co-occur (2); 44\% of community mental health team service users report SUD, with 75\% of drug service users and $85 \%$ of alcohol service users reporting one or more MD (3). MD and SUD are strongly associated with poorer than average health and greater risk of premature death (4). The terms 'co-occurring mental health and alcohol or drug use conditions' ('co-occurring conditions' or CC) and 'use' of substances are used in preference to 'Dual Diagnosis' and 'misuse', as they are more inclusive, not limited to formal diagnosis from a healthcare professional and include a range of reasons and methods for using substances (4), (5).

During the 1990s, prevalence of CC recorded in routine primary care data significantly increased (6). Recent studies have identified a complex epidemiological picture for MD and SUD in young people; incidence of anxiety and depression diagnosis is declining, but incidence of associated symptoms, and the prescription of antidepressants and anxiolytics, is increasing (7), (8), (9), (10). Survey data shows an increase in emotional disorders in young people, particularly older female adolescents [8]. Young people are drinking less alcohol (11), abstinence is increasing (12) and alcohol-related emergency admissions have decreased (13). However they are reporting greater levels of drug use (14), (15), and poisoning events associated with alcohol and opioids (including prescribed opioids) have increased, particularly among females using opioids. (16). Young people are at significantly increased risk of death or further emergency admission in the 10 year period following a drug or alcohol-related hospital admission (17) and SUD is a significant risk factor for progression to suicidal behaviour in young people who self-harm or express suicidal thoughts (18).

The authors are not aware of any recent studies using routine health data in the UK to examine trends and outcomes for children and young people with CC, and NICE has identified a need for research in this area (19). The aims of this study were to use routine health data from primary care, inpatient episodes and death registrations to estimate first recorded incidence of CC in children and young people aged 11-25 in Wales, UK, to estimate all-cause mortality rate and 10 year survival with CC in this population and to compare survival and mortality for individuals with codes for either CC, a record of either MD or SUD or no relevant codes recorded.

\section{Methods}

\section{Design}

A retrospective population-based electronic cohort study was conducted using linked routine primary care, hospital inpatient admissions and mortality data

\section{Data source}

The data source for this study was Secure Anonymised Information Linkage (SAIL) Databank, a secure repository established and managed by Swansea University Medical School. It houses anonymised health and related datasets, which can be linked for research purposes (20), (21). Datasets (Table 1) were prepared within the Adolescent Mental Health Data Platform (22). 


\begin{tabular}{|ll|}
\hline Dataset & Definition \\
\hline $\begin{array}{l}\text { The Welsh Demographic } \\
\text { Service Dataset (WDSD) }\end{array}$ & $\begin{array}{l}\text { Registration history of all individuals who have been registered with a GP practice in Wales. It includes start and end dates } \\
\text { of registration periods and address history. }\end{array}$ \\
$\begin{array}{l}\text { Welsh Longitudinal } \\
\text { General Practice dataset } \\
\text { (WLGP) }\end{array}$ & $\begin{array}{l}\text { Event history for each individual registered SAlL-supplying GP practice. Clinical information in the dataset is stored } \\
\text { primarily in the form of Read version two (Read v2) codes. This dataset does not cover the entire Welsh population; SAIL } \\
\text { currently receives data from approximately 80\% of GP practices in Wales. }\end{array}$ \\
$\begin{array}{l}\text { Patient Episodes Dataset } \\
\text { for Wales (PEDW) }\end{array}$ & $\begin{array}{l}\text { Event history of inpatient episodes taking place in Welsh hospitals, or where Welsh residents are treated in English } \\
\text { hospitals. }\end{array}$ \\
$\begin{array}{l}\text { Office of National } \\
\text { Statistics (ONS) Annual } \\
\begin{array}{l}\text { District Deaths Extract } \\
\text { (ADDE) }\end{array}\end{array}$ & $\begin{array}{l}\text { Death records for all individuals usually resident in Wales. It includes cause of death information derived from death } \\
\text { certificates }\end{array}$ \\
\hline
\end{tabular}

All data preparation and analysis was performed using IBM DB2 v11.1.4.4 and R software.

\section{Measures}

\section{Clinical coding for case definitions}

Read v2 codes: problem, harmful or hazardous substance use and co-occurring conditions

With clinical input and based on published literature (11), (23), (24) we compiled a list of SUD-related Read v2 codes, including diagnoses, symptoms, observations, medications, behaviours (e.g. 'injecting drug user'), referrals and contacts with other services. We included codes for alcohol or illegal drugs but excluded tobacco, in keeping with similar studies $(6,25)$. We included codes designating MD due to substance use, which were classified as CC without requiring the presence of a second MD or SUD code (for example Read v2 codes in section Eu\%, designating 'Mental and behavioural disorders due to psychoactive substance use'): this included codes for mental and behavioural disorders due to acute intoxication, as there is an association between contact with services for acute intoxication and subsequent suicide risk (26).

We included only those prescriptions relevant to treatment for substance use, and excluded those used primarily for pain management. We included disulfiram, naltrexone, lofexidine, acamprosate and methadone, as almost all recipients had a history of SUD. For buprenorphine we included only those Read v2 codes where $10 \%$ or fewer recipients had no history of SUD. We excluded alcohol Read v2 codes requiring an associated value of units, because we could not be confident that on their own these codes denote SUD.

\section{International Classification of Diseases (ICD-10) codes: problem, harmful or hazardous substance use and co-occurring conditions}

ICD-10 codes (27) were initially identified by cross-mapping with SUD Read v2 codes. We then searched the literature to identify any additional codes (23), (24), (28), (29), (30): these were cross-mapped and added to the Read code list, to ensure consistency. As with Read v2 codes, ICD-10 codes designating MD due to substance use were classified as CC.

Read v2 and ICD-10 codes: mental disorders

MD codes were sourced from the Adolescent Mental Health Data Platform (ADP) Concept Library (22). We included codes for depression, anxiety, severe mental illness (SMI; schizophrenia, schizotypal and delusional disorders, bipolar disorder, other mood-related disorders and other severe mental illness) (31), (7), (10), (32), eating disorders (33), Attention Deficit Hyperactivity Disorder (ADHD) (34), Autistic Spectrum Disorder (ASD) (34), conduct disorders (34) and developmental disorders (35). Codes included both diagnoses of conditions and associated symptoms, but not prescriptions associated with these conditions.

All code lists can be found in Additional File S1.

\section{Factors and covariates}

We obtained data on factors and covariates for age, sex, and Welsh Index of Multiple Deprivation (WIMD) 2011 quintile, an area-based measure of relative deprivation in Wales (36). We divided age into four groups; 11-14, 15-17, 18-21 and 22-25 years of age (collapsed into two groups; 11-17 and 18-25, where numbers were too low to report). Age was defined at the end of each reporting year for incidence and at the start of the study window for mortality and survival. Individuals with null or contradictory indicators for sex were excluded. WIMD was derived from the 2001 census Local Super Output Area (LSOA) in which individuals were registered at the end of each year (or next nearest available record) for incidence, and at the start of follow-up period (or nearest available record) for mortality and survival.

\section{Analysis methods: incidence}

\section{Individuals included}

Using WDSD as the primary population, we identified individuals having their 11th - 25th birthdays between 1st January 2008 and 31 st December 2017 (7), (10). We included only periods during which individuals were registered with a SAIL supplying GP practice. For analysis of WLGP data, we excluded the first six months of each GP registration period, to minimise the designation of prevalent cases as new incident cases due to re-recording of patient history when 
individuals move between GP practices (7), (10). We did not apply this exclusion to the inpatient data, as there is no retrospective coding in inpatients. The data collection start date was therefore the latest of; SAIL GP registration start date (plus six months for WLGP data); first day of 11th birthday year or 1st Jan 2008. The data collection end date was the earliest of SAIL GP registration end date; last day of 25th birthday year, date of death or 31 st December 2017. An individual could contribute more than one period of data; for example, where they had moved between SAIL and non-SAIL GP practices or migrated out of Wales and subsequently returned. The denominator for incidence was person years at risk (PYAR), to reflect individuals present in the data for only part of a year (6), (7), (10).

\section{MD and SUD indicators}

Incident cases were identified separately in primary care data (WLGP) and inpatient data (PEDW) using Read v2 and ICD-10 code lists. We excluded codes designating a history of a particular condition, as they do not distinguish between ongoing and historical conditions.

\section{Incidence measures}

First recorded incidence was defined as the date of the first occurrence in the patient history of a CC code, or in the absence of such a code, the latter of the first MD or the first SUD code (the first of which could appear at any time in the patient history). An incident event was recorded only once for each individual, regardless of how many periods of data they contributed to the study population.

We plotted annual first recorded incidence rates to describe trends over time. Poisson regression, with an offset allowing for comparison of rates, was undertaken to model counts of CC incidence by year, sex, age band and WIMD quintile. The degree of over-dispersion was estimated using the quasi-Poisson method (37) and as the data were found to be over-dispersed, standard errors from the quasi-Poisson model were used to derive $95 \%$ confidence intervals. Rates were reported as annual incidence per 1,000 PYAR and incidence rate ratios (IRR).

\section{Analysis methods: mortality}

We extracted from the incidence cohort a subset of individuals born between 1983 and 1997 and registered with a SAIL-supplying GP practice on 1 st January 2008. We followed these individuals for 10 years, from 1 st January 2008 to 31 st December 2017. Therefore, the oldest age cohort, (those born in 1983), was followed up from the year of their 25th birthday to year of their 34th birthday and the youngest age cohort (those born in 1997) was followed up from the year of their 11th birthday to the year of their 20th birthday. In this cohort each individual provided only one period of data; the start date of follow-up was 1 st January 2008 and the end date was the earliest of death, 31st December 2017 or last date of registration with a SAIL-supplying GP practice (date of loss to follow-up).

We searched the patient record to identify MD, SUD and CC codes occurring at any time between birth and end of follow-up, including codes designating a history of a particular condition. Using the ONS Annual District Deaths Extract (ADDE) we identified individuals who had died during the study window. We compared the proportion of deaths among those with a history of CC, either SUD or MD, and neither SUD or MD (NC). We calculated observed unadjusted mortality rates per 1,000 PYAR for each condition group, by age, sex and WIMD quintile.

We included individuals with no prior history of SUD, who died following a single episode involving use of a substance, in either the SUD or CC groups (depending on the codes in their history). We carried out a sensitivity analysis examining the impact of designating these individuals as NC.

\section{Analysis methods: survival}

Using the cohort of individuals present in SAIL on 1st January 2008, we estimated survival from start of follow up time (1st January 2008); the outcome variable was death. The exposure variable was condition group (NC; MD only; SUD only; CC). We right censored follow up time to the earliest of data collection end date or end of follow up. We plotted Kaplan Meier survival curves, with significance of difference assessed by log rank tests. We performed Cox regression to derive hazard ratios comparing risk of all-cause death for individuals with CC in their history with those with SUD or MD only and those with NC, adjusted for sex, WIMD quintile and age band at start of follow-up. We tested the proportional hazards assumption by plotting Schoenfeld residuals. We then repeated the analysis with condition group as a time-dependent variable (as recording of codes could occur at any time), WIMD quintile as a two-level group (60\% least deprived; $40 \%$ most deprived) and age at start of follow-up as a continuous instead of a categorical variable (38).

\section{Results}

\section{Study populations}

Figure 1 shows a flow diagram of the study cohorts. The WLGP incidence cohort consisted of 923,941 individuals contributing 4,391,444 PYAR (mean $=4.8$ years, $S D=3.2$ years) and the PEDW incidence cohort consisted of 958,603 individuals contributing 4,545,876 PYAR (mean $=4.7$ years, $S D=3.2$ years). The mortality cohort consisted of 465,242 individuals, contributing 3,746,991 years of person-time ( $m e a n=8.1$ years, $S D=3.1$ years), of whom 1,416 died during the 10-year follow-up period.

Table 2 summarises the proportion of the incidence cohorts with codes for SUD only, MD only or CC in their history. In the WLGP cohort, $75.4 \%$ were NC, $21.8 \%$ were MD only, $0.8 \%$ were SUD only and $2.0 \%$ were CC. $70.4 \%$ of individuals with SUD also had a code for MD and $8.4 \%$ of individuals with MD also had a code for SUD. In the PEDW cohort, $94.8 \%$ were NC, $2.9 \%$ were MD only, $0.5 \%$ were SUD only and $1.9 \%$ were CC. $79.7 \%$ of individuals with SUD also had a code for MD and $38.8 \%$ of individuals with MD also had a code for SUD. 
Table 2

WLGP and PEDW cohorts by condition group

\begin{tabular}{|c|c|c|c|c|}
\hline & & Total & $\mathbf{n}$ & $\%(95 \% \mathrm{Cl})$ \\
\hline \multirow[t]{6}{*}{ WLGP } & $\%$ of total with NC & 923941 & 696691 & $75.4(75.3-75.5)$ \\
\hline & $\%$ of total with MD only & 923941 & 200981 & $21.8(21.7-21.8)$ \\
\hline & $\%$ of total with SUD only & 923941 & 7778 & $0.8(0.8-0.9)$ \\
\hline & $\%$ of total with CC & 923941 & 18491 & $2.0(2.0-2.0)$ \\
\hline & $\%$ of MD with SUD & 219472 & 18491 & $8.4(8.3-8.5)$ \\
\hline & $\%$ of SUD with MD & 26269 & 18491 & $70.4(69.8-70.9)$ \\
\hline \multirow[t]{6}{*}{ PEDW } & $\%$ of total with NC & 958603 & 908363 & $94.8(94.7-94.8)$ \\
\hline & $\%$ of total with MD only & 958603 & 27985 & $2.9(2.9-3.0)$ \\
\hline & $\%$ of total with SUD only & 958603 & 4515 & $0.5(0.5-0.5)$ \\
\hline & $\%$ of total with CC & 958603 & 17740 & $1.9(1.8-1.9)$ \\
\hline & $\%$ of MD with SUD & 45725 & 17740 & $38.8(38.4-39.2)$ \\
\hline & $\%$ of SUD with MD & 22255 & 17740 & $79.7(79.2-80.2)$ \\
\hline
\end{tabular}

Table 3 summarises the condition groups of the 923,941 individuals present in both the WLGP and PEDW incidence cohorts, by sex and across both settings (primary care and hospital admission). Overall, a greater proportion of females than males had a record of $\mathrm{MD}$ in either setting (26.0, 95\% Cl 25.9-26.2 compared with $17.0,95 \% \mathrm{Cl} 16.9-17.1)$, whereas more males than females had a record for SUD or $\mathrm{CC}(1.0,95 \% \mathrm{Cl} 1.0-1.1 \mathrm{compared} \mathrm{with} 0.6 \%$, $95 \% \mathrm{Cl} 0.6-$ 0.6 for SUD and 3.9\%, 95\% Cl 3.9-4.0 compared with 3.1\%, 95\% Cl 3.0-3.1 for CC). A higher proportion of males than females had no record of a condition in either setting $(78.0 \%, 95 \% \mathrm{Cl} 77.9-78.1$ compared with $70.3 \%, 95 \% \mathrm{Cl} 70.2-70.4)$.

A greater proportion of females than males had only a primary care record with an $\mathrm{MD}(22.6 \%, 95 \% \mathrm{Cl} 22.4-22.7$ compared with $14.9 \%, 95 \% \mathrm{Cl} 14.9-15.0)$. In the WLGP SUD only and CC groups, the proportion of males with no PEDW record was greater than that for females; $0.8 \%$ (95\% CI $0.8-0.9)$ compared with $0.4 \%(95 \% \mathrm{Cl} 0.4-0.4)$ for SUD only and $1.3 \%(95 \% \mathrm{Cl} 1.3-1.4)$ compared with $0.8 \%(95 \% \mathrm{Cl} 0.8-0.9)$ for the CC group. Across both sexes, $86.2 \%$ of the WLGP MD only group (173,167 out of 200,891$), 74.0 \%$ of the WLGP SUD only group $(5,754$ out of 7,778$)$ and $53.7 \%$ of the WLGP CC group (9,933 out of 18,491$)$ had not had a relevant PEDW admission. Of the 696,691 individuals in the WLGP NC group, 5,754 (0.8\%) were MD only in PEDW, 1,505 (0.2\%) were SUD only in PEDW and 4,148 (0.6\%) were CC in PEDW. 
Table 3

Comparison of WLGP and PEDW by condition group

\begin{tabular}{|c|c|c|c|c|c|c|c|}
\hline & & \multicolumn{2}{|l|}{ MALE } & \multicolumn{2}{|l|}{ FEMALE } & \multicolumn{2}{|l|}{ TOTAL } \\
\hline & & $\mathbf{n}$ & $\%(95 \% \mathrm{Cl})$ & $\mathbf{n}$ & $\%(95 \% \mathrm{Cl})$ & $\mathbf{n}$ & $\%(95 \% \mathrm{Cl})$ \\
\hline \multirow[t]{4}{*}{ Across both settings } & MD only & 78415 & $17.0(16.9-17.1)$ & 120408 & $26.0(25.9-26.2)$ & 198823 & $21.5(21.4-21.6)$ \\
\hline & SUD only & 4809 & $1.0(1.0-1.1)$ & 2719 & $0.6(0.6-0.6)$ & 7528 & $0.8(0.8-0.8)$ \\
\hline & $\mathrm{CC}$ & 18166 & $3.9(3.9-4.0)$ & 14140 & $3.1(3.0-3.1)$ & 32306 & $3.5(3.5-3.5)$ \\
\hline & No condition & 360096 & $78.0(77.9-78.1)$ & 325188 & $70.3(70.2-70.4)$ & 685284 & $74.2(74.1-74.3)$ \\
\hline \multirow[t]{4}{*}{ WLGP: MD only } & PEDW: MD only & 6828 & $1.5(1.4-1.5)$ & 13074 & $2.8(2.8-2.9)$ & 19902 & $2.2(2.1-2.2)$ \\
\hline & PEDW: SUD only & 660 & $0.1(0.1-0.2)$ & 1329 & $0.3(0.3-0.3)$ & 1989 & $0.2(0.2-0.2)$ \\
\hline & PEDW: CC & 2641 & $0.6(0.6-0.6)$ & 3282 & $0.7(0.7-0.7)$ & 5923 & $0.6(0.6-0.7)$ \\
\hline & PEDW: No condition & 68792 & $14.9(14.8-15)$ & 104375 & $22.6(22.4-22.7)$ & 173167 & $18.7(18.7-18.8)$ \\
\hline \multirow[t]{4}{*}{ WLGP: SUD only } & PEDW: MD only & 63 & $0.0(0.0-0.0)$ & 35 & $0.0(0.0-0.0)$ & 98 & $0.0(0.0-0.0)$ \\
\hline & PEDW: SUD only & 157 & $0.0(0.0-0.0)$ & 112 & $0.0(0.0-0.0)$ & 269 & $0.0(0.0-0.0)$ \\
\hline & PEDW: CC & 1110 & $0.2(0.2-0.3)$ & 547 & $0.1(0.1-0.1)$ & 1657 & $0.2(0.2-0.2)$ \\
\hline & PEDW: No condition & 3904 & $0.8(0.8-0.9)$ & 1850 & $0.4(0.4-0.4)$ & 5754 & $0.6(0.6-0.6)$ \\
\hline \multirow[t]{4}{*}{ WLGP: CC } & PEDW: MD only & 888 & $0.2(0.2-0.2)$ & 1062 & $0.2(0.2-0.2)$ & 1950 & $0.2(0.2-0.2)$ \\
\hline & PEDW: SUD only & 380 & $0.1(0.1-0.1)$ & 342 & $0.1(0.1-0.1)$ & 722 & $0.1(0.1-0.1)$ \\
\hline & PEDW: CC & 3352 & $0.7(0.7-0.8)$ & 2534 & $0.5(0.5-0.6)$ & 5886 & $0.6(0.6-0.7)$ \\
\hline & PEDW: No condition & 6096 & $1.3(1.3-1.4)$ & 3837 & $0.8(0.8-0.9)$ & 9933 & $1.1(1.1-1.1)$ \\
\hline \multirow[t]{5}{*}{ WLGP: No condition } & PEDW: MD only & 2795 & $0.6(0.6-0.6)$ & 2959 & $0.6(0.6-0.7)$ & 5754 & $0.6(0.6-0.6)$ \\
\hline & PEDW: SUD only & 748 & $0.2(0.2-0.2)$ & 757 & $0.2(0.2-0.2)$ & 1505 & $0.2(0.2-0.2)$ \\
\hline & PEDW: CC & 2976 & $0.6(0.6-0.7)$ & 1172 & $0.3(0.2-0.3)$ & 4148 & $0.4(0.4-0.5)$ \\
\hline & PEDW: No condition & 360096 & $78.0(77.9-78.1)$ & 325188 & $70.3(70.2-70.4)$ & 685284 & $74.2(74.1-74.3)$ \\
\hline & Total & 461486 & & 462455 & & 923941 & \\
\hline
\end{tabular}

Of the 1,416 individuals in the mortality cohort who died during follow-up, 1020 (72.0\%) were male and 396 (28.0\%) were female. 607 (42.9\%) were NC, 417 (29.4\%) were MD only, 60 (4.2\%) were SUD only and 332 (23.4\%) were CC ( $0.2 \%$ of the NC group, $0.3 \%$ of MD only, $0.9 \%$ of SUD only and $1.2 \%$ of CC). Of the 165,835 individuals with MD and/or SUD, 809 (0.5\%) died during follow-up.

\section{Incidence}

Figure 2 and Fig. 3 summarise trends in CC incidence rate per 1,000 PYAR between 2008 and 2017 by sex, age and WIMD quintile, presented separately for WLGP and PEDW. Table 4 summarises the incidence of CC by sex, age, WIMD and year, including IRRs derived from the Quasi-Poisson regression.

Overall incidence in WLGP significantly reduced over the period $(2.5 / 1,000,95 \% \mathrm{Cl} 2.3-2.6$ in 2008 and $2.1 / 1,000,95 \% \mathrm{Cl} 2.0-2.2$ in $2017, \mathrm{IRR}=0.9,95 \% \mathrm{Cl} 0.8-$ $1.0, \mathrm{p}=0.01)$. Incidence in PEDW was stable $(2.3 / 1,000,95 \% \mathrm{Cl} 2.1-2.4$ in 2008 and $2.2 / 1,000,95 \% \mathrm{Cl} 2.0-2.3$ in $2017, \mathrm{IRR}=1.0,95 \% \mathrm{Cl} 0.9-1.1$, nonsignificant).

Incidence for males $(\mathrm{WLGP}=2.5 / 1,000,95 \% \mathrm{Cl} 2.5-2.6$; $\mathrm{PEDW}=2.4 / 1,000,95 \% \mathrm{Cl} 2.3-2.4)$ was significantly higher than for females $(\mathrm{WLGP}=2.1 / 1,000,95 \%$ $\mathrm{Cl}$ 2.0-2.1; PEDW $=1.9 / 1,000,95 \% \mathrm{Cl} 1.9-2.0)$, with IRR $=1.2(95 \% \mathrm{Cl} 1.2-1.3, \mathrm{p}=<0.01)$ for both WLGP and PEDW. Incidence among females in WLGP (but not PEDW) declined whereas for males it remained stable; incidence from WLGP for females in 2008 was 2.3/1,000 (95\% Cl 2.1-2.5) and in 2017 was $1.8 / 1,000$ $(95 \% \mathrm{Cl} 1.6-2.0)$.

Higher incidence was significantly related to increasing age: incidence in WLGP increased from $0.2 / 1,000(95 \% \mathrm{Cl} 0.1-0.2)$ for $11-14$ year olds to $3.8 / 1,000$ $(95 \% \mathrm{Cl} 3.7-3.9)$ for $22-25$ year olds (IRR $=25.1,95 \% \mathrm{Cl} 20.1-31.9, \mathrm{p}<0.01)$; and in PEDW from 0.6/1,000 $(95 \% \mathrm{Cl} 0.6-0.6)$ for $11-14$ year olds to $2.8 / 1,000$ $(95 \% \mathrm{Cl} 2.7-2.9)$ for $22-25$ year olds (IRR $=4.7,95 \% \mathrm{Cl} 4.2-5.2, \mathrm{p}<0.01)$. The association between higher incidence and increasing age was stronger for primary care than for hospital admissions, with rates in WLGP lower than in PEDW in the youngest age band but higher in the oldest; this was evident in greater IRRs in WLGP between age bands.

Higher incidence was associated with greater deprivation; the lowest incidence rates were among the least deprived quintile (WLGP $=1.1 / 1,000,95 \% \mathrm{Cl} 1.1-$ 1.2; PEDW = 1.2/1,000, 95\% Cl 1.2-1.3;) with the highest among the most deprived quintile (WLGP = 3.7/1,000, 95\% $\mathrm{Cl} 3.6-3.9$; PEDW $=3.2 / 1,000,95 \% \mathrm{Cl} 3.1-$ 3.3), IRR (WLGP) = $3.3(95 \% \mathrm{Cl} 3.0-3.7)$ and IRR (PEDW) = 2.6, 95\% Cl 2.4-2.9, with rates declining in the intermediate quintiles as deprivation reduced. Between 2008 and 2017, the gap between most and least deprived quintiles reduced considerably in WLGP, with a significant reduction in the most deprived quintile 
and a smaller, non-significant increase in the least deprived quintile; in 2008, incidence was 4.5/1,000 (95\% $\mathrm{Cl} 4.1-4.9)$ in the most deprived quintile and $1.0 / 1,000$ (95\% $\mathrm{Cl} 0.8-1.2)$ in the least deprived quintile; by 2017 incidence was $3.0 / 1,000(95 \% \mathrm{Cl} 2.7-3.4)$ in the most deprived quintile and $1.4 / 1,000$ (95\% $\mathrm{Cl} 1.1-1.7)$ in the least deprived quintile. This was not observed to the same extent in PEDW.

Table 4

Incidence of CC and IRR by sex, age band, WIMD and year

\begin{tabular}{|c|c|c|c|c|c|c|c|}
\hline & & WLGP events & & & PEDW events & & \\
\hline & & Incidence $(95 \% \mathrm{Cl})$ & IRR (95\%Cl) & $\mathrm{p}$ value & Incidence $(95 \% \mathrm{Cl})$ & IRR (95\%Cl) & $\mathrm{p}$ value \\
\hline \multirow[t]{2}{*}{ Sex } & Female & $2.1(2.0-2.1)$ & ref & & $1.9(1.9-2)$ & ref & \\
\hline & Male & $2.5(2.5-2.6)$ & $1.2(1.2-1.3)$ & 0.00 & $2.4(2.3-2.4)$ & $1.2(1.2-1.3)$ & 0.00 \\
\hline \multirow[t]{4}{*}{ Age band } & $11-14$ & $0.2(0.1-0.2)$ & ref & & $0.6(0.6-0.6)$ & ref & \\
\hline & $15-17$ & $1.2(1.2-1.3)$ & $8.1(6.4-10.4)$ & 0.00 & $2.2(2.1-2.3)$ & $3.6(3.2-4.1)$ & 0.00 \\
\hline & $18-21$ & $3.3(3.2-3.4)$ & $22(17.6-27.9)$ & 0.00 & $2.8(2.7-2.9)$ & $4.8(4.3-5.4)$ & 0.00 \\
\hline & $22-25$ & $3.8(3.7-3.9)$ & $25.1(20.1-31.9)$ & 0.00 & $2.8(2.7-2.9)$ & $4.7(4.2-5.2)$ & 0.00 \\
\hline WIMD & 1 (least depr) & $1.1(1.1-1.2)$ & ref & & $1.2(1.2-1.3)$ & ref & \\
\hline \multirow[t]{5}{*}{ Quintile } & 2 & $1.6(1.5-1.7)$ & $1.4(1.3-1.6)$ & 0.00 & $1.6(1.6-1.7)$ & $1.3(1.2-1.5)$ & 0.00 \\
\hline & 3 & $2.1(2.0-2.2)$ & $1.9(1.7-2.1)$ & 0.00 & $2.1(2.0-2.2)$ & $1.7(1.6-1.9)$ & 0.00 \\
\hline & 4 & $2.8(2.6-2.9)$ & $2.4(2.2-2.7)$ & 0.00 & $2.5(2.4-2.6)$ & $2.0(1.8-2.2)$ & 0.00 \\
\hline & 5 (most depr) & $3.7(3.6-3.9)$ & $3.3(3.0-3.7)$ & 0.00 & $3.2(3.1-3.3)$ & $2.6(2.4-2.9)$ & 0.00 \\
\hline & $\mathrm{n} / \mathrm{a}$ & $0.5(0.3-0.7)$ & $0.3(0.2-0.6)$ & 0.00 & $1.1(0.9-1.4)$ & $0.8(0.6-1.0)$ & 0.11 \\
\hline \multirow[t]{10}{*}{ Year } & 2008 & $2.5(2.3-2.6)$ & ref & & $2.3(2.1-2.4)$ & ref & \\
\hline & 2009 & $2.6(2.4-2.7)$ & $1.0(0.9-1.2)$ & 0.69 & $2.3(2.2-2.4)$ & $1.0(0.9-1.1)$ & 0.88 \\
\hline & 2010 & $2.5(2.3-2.6)$ & $1.0(0.9-1.1)$ & 0.67 & $2.1(2.0-2.2)$ & $0.9(0.8-1.0)$ & 0.20 \\
\hline & 2011 & $2.2(2.1-2.4)$ & $0.9(0.8-1.0)$ & 0.06 & $2.2(2.1-2.3)$ & $1.0(0.9-1.1)$ & 0.54 \\
\hline & 2012 & $2.3(2.2-2.4)$ & $0.9(0.8-1.0)$ & 0.11 & $2.2(2.0-2.3)$ & $0.9(0.8-1.1)$ & 0.31 \\
\hline & 2013 & $2.4(2.2-2.5)$ & $0.9(0.8-1.1)$ & 0.34 & $2.3(2.2-2.5)$ & $1.0(0.9-1.1)$ & 0.82 \\
\hline & 2014 & $2.2(2.1-2.3)$ & $0.9(0.8-1.0)$ & 0.03 & $1.9(1.8-2.0)$ & $0.8(0.7-0.9)$ & 0.00 \\
\hline & 2015 & $2.2(2.1-2.3)$ & $0.9(0.8-1.0)$ & 0.03 & $2.2(2.1-2.3)$ & $1.0(0.9-1.1)$ & 0.58 \\
\hline & 2016 & $2.1(2.0-2.2)$ & $0.8(0.7-1.0)$ & 0.01 & $2.0(1.8-2.1)$ & $0.9(0.8-1.0)$ & 0.02 \\
\hline & 2017 & $2.1(2.0-2.2)$ & $0.9(0.8-1.0)$ & 0.01 & $2.2(2.0-2.3)$ & $1.0(0.9-1.1)$ & 0.59 \\
\hline
\end{tabular}

\section{Mortality}

Figure 4 summarises observed unadjusted mortality rates for each condition group per 1,000 PYAR, by sex, age at start of follow-up and WIMD quintile. The highest rate was for individuals with CC (1.4/1,000 PYAR, 95\% Cl 1.2-1.5), followed by those with SUD only $(1.1 / 1,000,95 \% \mathrm{Cl} 0.9-1.4)$; these rates were not significantly different but both were significantly higher than rates for MD only $(0.4 / 1,000,95 \% \mathrm{Cl} 0.3-0.4)$ and for $\mathrm{NC}(0.3 / 1,000,95 \% \mathrm{Cl} 0.2-0.3)$. Rates were significantly higher for males than females for all condition groups except SUD only, and were significantly higher for 18-25 year olds than 11-17 year olds for all condition groups except SUD only. Rates for the most deprived WIMD quintile were higher than any of the other quintiles, but other than in the NC group (most deprived $=0.3 / 1,000,95 \% \mathrm{Cl} 0.3-0.4$, least deprived $=0.2 / 1,000,95 \% \mathrm{Cl} 0.2-0.2$ ) there were no significant differences by deprivation other than between the most deprived quintile $(1.6,1,000,95 \% \mathrm{Cl} 1.4-1.9)$ and the second least deprived quintile $(0.9 / 1,000,95 \% \mathrm{Cl} 0.6-1.3)$ in the $\mathrm{CC}$ group.

Of 392 deaths among the SUD only and CC groups, we identified six who died in hospital with no prior history of SUD before their final admission. Reclassifying these as NC in the analysis made no significant difference.

\section{Survival}

Figures 5-11 show plots of Kaplan-Meier survival curves with p-values derived from Log Rank tests, by condition group, sex, age band and WIMD quintile. Due to risk of statistical disclosure arising from small counts, the curves for SUD only were excluded from Figs. 6-11. To further prevent statistical disclosure, age band and WIMD quintile were collapsed to two levels (11-17 and 18-25; least deprived $60 \%$, or quintiles $1-3$ and most deprived $40 \%$, or quintiles 4 and 5 ).

Survival was significantly different for individuals with CC, NC or MD only, for both males and females $(p<0.0001$, Fig. 5). Figures $6-11$ show that survival for males was significantly lower than for females in all condition groups and in both age bands at $p<0.0001$, and for $11-17$ year olds with $\mathrm{CC}$ at $\mathrm{p}<0.05$. The 
group who were 18-25 at follow-up start had significantly lower survival for all conditions (all significant at $p<0.01$ ) except females with NC where there was no significant difference by age. Results by WIMD group were mixed; survival for both males and females with NC was significantly lower for the more deprived group (females $=p<0.05$; males $=p<0.001$ ). Differences in survival between the least and most deprived females with MD only and CC, and between the least and most deprived males with CC were not significant; differences between the least and most deprived males with MD only were significant at $p<$ 0.05 .

Figure 12 summarises the results of a Cox regression with death from all cause as the outcome. Results showed that compared to the NC group, the risk of death during the study window was significantly higher for individuals with MD only ( $\mathrm{HR}=2.7,95 \% \mathrm{Cl} 2.4-3.1, \mathrm{p}<0.001)$, with SUD only (HR=4.5, 95\% $\mathrm{Cl} 3.4-$ $5.9, \mathrm{p}<0.001)$ and with $\mathrm{CC}(\mathrm{HR}=8.7,95 \% \mathrm{Cl} 7.5-10.0, \mathrm{p}<0.001)$.

\section{Discussion}

\section{Main findings in the context of previous studies}

In keeping with previous studies we found a high degree of overlap between cases of MD and SUD (2), (1), (3), particularly for SUD in secondary care where almost $80 \%$ with SUD also had an MD, as shown in Table 2. The overlap for MD, particularly in primary care, was lower, with around $8 \%$ of those with MD also having a record of an SUD; this may reflect the large proportion of patients with MD who are managed in primary care without ever being admitted to hospital.

Incidence of CC in young people aged 11-25 between 2008 and 2017 was stable in secondary care and decreased in primary care, particularly for females and among 11-17 year olds, with significantly higher rates associated with male sex, increasing age and greater deprivation. Higher incidence was associated with male sex, older age and greater deprivation, as shown in Fig. 2, Fig. 3 and Table 4. Similar trends have been identified in studies using routine data to separately estimate incidence or prevalence of MD (7), (9), (10), (31) and SUD (11), (13). The gap in primary care incidence rates between the most and least deprived quintiles has reduced, due to a reduction in incidence in the most deprived quintile.

Observed unadjusted mortality was significantly higher among individuals with a diagnosis of CC, and to a lesser extent among those with a diagnosis of SUD or MD only, than among individuals with NC, as shown in Fig. 4. Survival was significantly lower for individuals with CC, particularly for males and those in the older age band at follow-up start, as shown in Figs. 6-11. Compared to the NC group, the hazard ratio for death was 8.7 times greater in the CC group, 4.5 times greater in the SUD only group and 2.7 times greater in the MD only group, as shown in Fig. 12. Alcohol and drug use have been shown to commonly precede suicide (39). Our findings are consistent with previous studies suggesting individuals with a history of alcohol use disorder are at significantly increased risk of death (26), even in the absence of a co-occurring MD (40). MD (particularly with comorbid SUD) is associated with all-cause mortality rates significantly higher than those for the general population: as well as the inherent risk of death directly attributable to substance use, there may be greater medical morbidity, which is not always well recognised by service providers (41). There is a well-established association between deprivation, male sex and increased risk of death (42). Higher mortality but lower contact with services among males may indicate greater unmet need in this group, although no association can be assumed without further analysis by specific cause of death.

\section{Strengths and limitations}

This was a large-scale population study using linked routine health data comprising the records of nearly one million participants in Wales, providing a sufficiently large number of outcomes (CC cases and deaths) to support our estimations. We used the ONS ADDE to ascertain date of death, which is a nearcomplete record and is considered the gold standard for death records (43). Although the SAIL Databank dataset holds records for 77\% of GP practices (and $79 \%$ of the current population) in Wales, the data in SAIL is broadly representative of the Welsh population in terms of sex, age and deprivation. Routine data may vary in quality between sources, and this may affect dataset linkage; to mitigate this we used only those records where there was sufficient level of confidence in matching quality (21).

Alcohol use disorders, particularly hazardous and harmful drinking (as opposed to dependent drinking) are under-recorded by GPs, particularly for men and younger people (44). This is also likely to be the case for illicit drug use (45), (46). Rates of recording may vary over time or between GP practices, due to experience, training, practice protocols and government policies (47). The exclusion of codes relating to consumption levels may also mean that some individuals with problematic, hazardous or harmful alcohol consumption are not detected. This means that estimated rates of SUD derived from routine primary care data should be considered as a minimum. The analysis should be interpreted as examining coding behaviour as much as clinical indicators (33).

The identification of cases within this study is limited by the availability of full patient history in the WLGP and PEDW datasets. We did not include individuals attending Emergency Departments; inclusion of this dataset would very likely increase the incidence of CC as it would include individuals not admitted to hospital and those who are reluctant to seek help from their GP. Incident cases are defined as the first recorded occurrence of a code, but we cannot be certain that these events genuinely represent the onset of a condition (48). The rates presented are therefore a measure of contacts with services (49).

We estimated mortality and survival for death from all causes, and did not consider specific causes. SUD and MD are (both individually and in combination) associated with an increased risk of death from specific causes such as suicide, as well as deaths from natural causes (39), (26), (40), (41), (17), (23), (32).

We did not include personality disorders (PD) in our definition of MD, although PD commonly co-occurs with SUD (50); this is because SUD is considered a diagnostic criterion for borderline personality disorder (51). We grouped together use of alcohol and drugs, and did not consider the impact of specific substances, the severity of usage or the impact of using specific combinations of substances. We have included SUD codes indicating varying degrees of 
severity; for example we included as CC all episodes with codes for mental or behavioural disorders due to psychoactive substance use, which includes episodes of acute intoxication "resulting in disturbances in level of consciousness, cognition, perception, affect or behaviour" (27).

\section{Policy, research and practice implications}

Individuals who have had contact with primary care or inpatient services related to CC (as well as those with SUD or MD only) in their patient history are at significantly increased risk of death; these contacts may offer an opportunity to identify particularly vulnerable individuals in need of specialist intervention.

CC incidence rates for younger age bands were lower in primary care than in hospital admissions, which was unexpected, given that GP practices should receive and record notification of any inpatient admissions and that primary care may be the first place individuals turn to for help with SUD (47). This finding supports existing evidence of under-recording of SUD in primary care (but in this instance may relate to the recording of SUD, MD or both). There are well documented sensitivities about discussing and recording SUD in primary care (47) which may be amplified for younger patients. Survival and mortality rates were significantly poorer for individuals with CC, but were also significantly worse for individuals with SUD only, suggesting that SUD (with or without cooccurring MD) is a key risk factor, particularly for males. Alternatively this may be due to undiagnosed MD among substance users.

This study did not consider subcategories of death; however it is likely that risks of natural and unnatural death (particularly suicide) are not equal, and are affected by the presence or absence of $\mathrm{CC}$. This may also be the case for risk of non-lethal self-harm among individuals with $\mathrm{CC}$, which was not considered in this study. Risk may vary according to the type and combination of substance used, particularly whether both alcohol and drugs are used.

\section{Conclusion}

CC significantly increases the risk of death in children and young people aged 11-25. Incidence of CC in children and young people in Wales between 2008 and 2017 decreased in primary care and remained stable in secondary care, with significantly higher incidence associated with male sex, increasing age and greater deprivation. Mortality was significantly higher among individuals with a diagnosis of CC, and to a lesser extent among those with a diagnosis of SUD or MD only, compared with individuals with NC. The higher mortality rate for individuals with SUD (with or without mental disorder) may indicate substance use as a key risk factor, or alternatively may be indicative of unrecorded mental disorder in substance using individuals.

\section{List Of Abbreviations}

\begin{tabular}{|ll|}
\hline Abbreviation & Definition \\
\hline ADDE & Annual District Deaths Extract \\
\hline ADP & Adolescent Mental Health Data Platform \\
\hline IRR & Co-ocurring conditions \\
\hline LSOA & Incidence rate ratio \\
\hline MD & Local Super-Output Area \\
\hline NC & Mental disorder \\
\hline PEDW & Neither condition (no MD or SUD) \\
\hline PYAR & Patient Episode Dataset for Wales \\
\hline SAIL Databank & Person years at risk \\
\hline SUD & Problem, hazardous or harmful substance use \\
\hline WDSD & Welsh Demographic Service Dataset \\
\hline WIMD & Welsh Index of Multiple Deprivation \\
\hline WLGP & Welsh Longitudinal GP Dataset \\
\hline
\end{tabular}

\section{Declarations}

\section{Ethical approval and consent to participate}

The study was approved by the SAIL Databank Information Governance Review Panel (IGRP), an independent body comprising representatives from a range of organisations including the British Medical Association (BMA) Cymru, Welsh Government, Public Health Wales, National Research Ethics Service, NHS Wales Informatics Service (NWIS), Swansea Bay University Local Health Board and members of the public. As the study utilised only anonymised data, informed consent was not required. The study was approved under IGRP number 0667.

\section{Consent for publication}

Not applicable 


\section{Availability of data and materials}

This study utilises data hosted by the SAIL Databank, Swansea University Medical School. These data are not publicly available, but can be accessed for research purposes subject to approval by the SAIL Databank Information Governance Review Panel (IGRP). Further information about the SAIL Databank application process is available at https://saildatabank.com/application-process/

\section{Competing interests}

The authors declare that they have no competing interests.

\section{Funding}

This work was funded by the Adolescent Mental Health Data Platform (ADP). The ADP is funded by MQ Mental Health Research Charity (Grant Reference MQBF/3 ADP).

\section{Authors' contributions}

Study conception: AJ and SR. Study design: SR, AJ and JK. Clinical guidance including creation of code lists: AJ and JK. Data preparation: SR. Statistical analysis: SR, AJ and AW. Original draft written by SR and AJ. Draft and final manuscript edited and reviewed by all authors.

\section{Acknowledgements}

ADP and the author(s) would like to acknowledge the data providers who supplied the datasets enabling this research study. The views expressed are entirely those of the authors and should not be assumed to be the same as those of ADP or MQ Mental Health Research Charity.

This study makes use of anonymised data held in the Secure Anonymised Information Linkage (SAIL) Databank (project number 0667). We would like to acknowledge all the data providers who make anonymised data available for research. This work uses data provided by patients and collected by the NHS as part of their care and support.

\section{References}

1. Whiteford HA, Degenhardt L, Rehm J, Baxter AJ, Ferrari AJ, Erskine HE, et al. Global burden of disease attributable to mental and substance use disorders: Findings from the Global Burden of Disease Study 2010. Lancet. 2013;382(9904):1575-86.

2. Lai HMX, Cleary M, Sitharthan T, Hunt GE. Prevalence of comorbid substance use, anxiety and mood disorders in epidemiological surveys, 1990-2014: A systematic review and meta-analysis. Vol. 154, Drug and Alcohol Dependence. Elsevier Ireland Ltd; 2015. p. 1-13.

3. Weaver T, Madden P, Charles V, Stimson G, Renton A, Tyrer P, et al. Comorbidity of substance misuse and mental illness in community mental health and substance misuse services. Br J Psychiatry. 2003 Oct 1;183(OCT.):304-13.

4. Christie E. Better care for people with co-occurring mental health and alcohol/drug use conditions A guide for commissioners and service providers. 2017;8. Available from: https://assets.publishing.service.gov.uk/government/uploads/system/uploads/attachment_data/file/625809/Cooccurring_mental_health_and_alcohol_drug_use_conditions.pdf

5. Todd J, Green G, Harrison M, Ikuesan BA, Self C, Baldacchino A, et al. Defining dual diagnosis of mental illness and substance misus some methodological issues. J Psychiatr Ment Health Nurs. 2004 Feb;11(1):48-54.

6. Frisher M, Collins J, Millson D, Crome I, Croft P. Prevalence of comorbid psychiatric illness and substance misuse in primary care in England and Wales. J Epidemiol Community Heal [Internet]. 2004 Dec 1 [cited 2019 Jun 4];58(12):1036-41. Available from: http://www.ncbi.nlm.nih.gov/pubmed/15547069

7. John A, Marchant AL, McGregor J., Tan JOA, Hutchings HA, Kovess V, et al. Recent trends in the incidence of anxiety and prescription of anxiolytics and hypnotics in children and young people: An e-cohort study. J Affect Disord [Internet]. 2015 Sep [cited 2019 Mar 20];183:134-41. Available from: https://linkinghub.elsevier.com/retrieve/pii/S0165032715002943

8. NHS. Mental Health of Children and Young People in England, 2017: Trends and characteristics. 2018;(November):1-45. Available from: https://files.digital.nhs.uk/9B/518A64/MHCYP 2017 Trends Characteristics.pdf

9. Wijlaars LPMM, Nazareth I, Petersen I. Trends in depression and antidepressant prescribing in children and adolescents: a cohort study in The Health Improvement Network (THIN). PLoS One [Internet]. 2012 Jan 13 [cited 2016 Sep 5];7(3):e33181. Available from:

http://dx.doi.org/10.1371/journal.pone.0033181

10. John A, Marchant AL, Fone DL, McGregor JI, Dennis MS, Tan JOA, et al. Recent trends in primary-care antidepressant prescribing to children and young people: an e-cohort study. Psychol Med [Internet]. 2016 Dec 8 [cited 2019 Mar 20];46(16):3315-27. Available from: http://www.journals.cambridge.org/abstract_S0033291716002099

11. Thompson A, Wright AK, Ashcroft DM, van Staa TP, Pirmohamed M. Epidemiology of alcohol dependence in UK primary care: Results from a large observational study using the Clinical Practice Research Datalink. Lin ZC, editor. PLoS One [Internet]. 2017 Mar 31 [cited 2019 Jun 20];12(3):e0174818. Available from: http://dx.plos.org/10.1371/journal.pone.0174818

12. Ng Fat L, Shelton N, Cable N. Investigating the growing trend of non-drinking among young people; Analysis of repeated cross-sectional surveys in England 2005-2015. Vol. 18, BMC Public Health. BioMed Central Ltd.; 2018.

13. Trefan L, Gartner A, Alcock A, Farewell D, Morgan J, Fone D, et al. Epidemiology of alcohol-related emergency hospital admissions in children and adolescents: An e-cohort analysis in Wales in 2006-2011. Boniface S, editor. PLoS One [Internet]. 2019 Jun 4 [cited 2019 Nov 26];14(6):e0217598.

Page $10 / 19$ 
Available from: http://dx.plos.org/10.1371/journal.pone.0217598

14. NHS Digital. Smoking, Drinking and Drug Use among Young People in England 2018 [Internet]. 2019 [cited 2020 Feb 10]. Available from: https://digital.nhs.uk/data-and-information/publications/statistical/smoking-drinking-and-drug-use-among-young-people-in-england/2018

15. Office H. Drug misuse: findings from the 2018 to 2019 CSEW [Internet]. [cited 2019 Nov 25]. Available from: https://www.gov.uk/government/organisations/home-office/series/drug-misuse-declared

16. Tyrrell EG, Kendrick D, Sayal K, Orton E. Poisoning substances taken by young people: a population-based cohort study. Br J Gen Pract [Internet]. 2018 Oct [cited 2019 Mar 20];68(675):e703-10. Available from: http://bjgp.org/lookup/doi/10.3399/bjgp18X698897

17. Herbert A, Gilbert R, González-Izquierdo A, Pitman A, Li L. 10-y Risks of Death and Emergency Re-admission in Adolescents Hospitalised with Violent, Drug- or Alcohol-Related, or Self-Inflicted Injury: A Population-Based Cohort Study. Hay PJ, editor. PLOS Med [Internet]. 2015 Dec 29 [cited 2019 Mar 6];12(12):e1001931. Available from: http://www.ncbi.nlm.nih.gov/pubmed/26714280

18. Mars B, Heron J, Klonsky ED, Moran P, O'Connor RC, Tilling K, et al. Predictors of future suicide attempt among adolescents with suicidal thoughts or nonsuicidal self-harm: a population-based birth cohort study. The lancet Psychiatry [Internet]. 2019 Apr 1 [cited 2019 Aug 7];6(4):327-37. Available from: http://www.ncbi.nlm.nih.gov/pubmed/30879972

19. NICE. Coexisting severe mental illness and substance misuse: community health and social care services [Internet]. NICE; 2016 [cited 2020 Feb 10]. Available from: https://www.nice.org.uk/guidance/ng58

20. Ford D V., Jones KH, Verplancke JP, Lyons RA, John G, Brown G, et al. The SAIL Databank: Building a national architecture for e-health research and evaluation. BMC Health Serv Res. 2009;9.

21. Lyons RA, Jones KH, John G, Brooks CJ, Verplancke JP, Ford D V., et al. The SAIL databank: Linking multiple health and social care datasets. BMC Med Inform Decis Mak. 2009;9(1).

22. The Platform - Adolescent Mental Health Data Platform [Internet]. [cited 2019 Dec 9]. Available from: https://adolescentmentalhealth.uk/Platform

23. DelPozo-Banos M, John A, Petkov N, Berridge DM, Southern K, LLoyd K, et al. Using Neural Networks with Routine Health Records to Identify Suicide Risk: Feasibility Study. JMIR Ment Heal 2018;5(2)e10144 https//mental.jmir.org/2018/2/e10144/ [Internet]. 2018 Jun 22 [cited 2019 Feb 27];5(2):e10144. Available from: https://mental.jmir.org/2018/2/e10144/

24. Syed S, Gilbert R, Wolpert M. Parental alcohol misuse and the impact on children: a rapid evidence review of service presentations and interventions [Internet]. London; 2018 [cited 2019 Jun 20]. Available from: https://www.ucl.ac.uk/children-policy-research/sites/children-policy-research/files/parentalalcohol-misuse-and-impact-on-children.pdf

25. Frisher M. Substance misuse and psychiatric illness: prospective observational study using the general practice research database. J Epidemiol Community Heal [Internet]. 2005 Oct 1 [cited 2019 Jun 4];59(10):847-50. Available from: http://jech.bmj.com/cgi/doi/10.1136/jech.2004.030833

26. Bowden B, John A, Trefan L, Morgan J, Farewell D, Fone D. Risk of suicide following an alcohol-related emergency hospital admission: An electronic cohort study of 2.8 million people. Abe T, editor. PLoS One [Internet]. 2018 Apr 27 [cited 2019 Mar 12];13(4):e0194772. Available from: http://dx.plos.org/10.1371/journal.pone.0194772

27. Organization WH. The International Classification of Diseases ICD-10 [Internet]. ICD 10: 2016. 2016. Available from: http://apps.who.int/classifications/icd10/browse/2016/en

28. Walsh E, Jones R, Cox S. Data mining Wales: The annual profile for substance misuse 2017-18 [Internet]. [cited 2019 Jun 20]. Available from: http://www.wales.nhs.uk/sitesplus/documents/888/FINAL Annual Profile for Substance Misuse 2017-18.pdf

29. NHS National Services Scotland. Alcohol-related hospital statistics Scotland 2017/18 [Internet]. 2019 [cited 2019 Jun 20]. Available from: https://www.statisticsauthority.gov.uk/national-statistician/types-of-official-statistics/

30. NHS National Services Scotland. Drug-Related Hospital Statistics Scotland 2017/18 [Internet]. 2019 [cited 2019 Jun 20]. Available from: https://www.isdscotland.org/Health-Topics/Drugs-and-Alcohol-Misuse/Publications/2019-05-28/2019-05-28-DRHS-Report.pdf

31. John A, McGregor J, Fone D, Dunstan F, Cornish R, Lyons RA, et al. Case-finding for common mental disorders of anxiety and depression in primary care: an external validation of routinely collected data. BMC Med Inform Decis Mak [Internet]. 2016 Dec 15 [cited 2019 Aug 8];16(1):35. Available from: http://www.ncbi.nlm.nih.gov/pubmed/26979325

32. John A, McGregor J, Jones I, Lee SC, Walters JTR, Owen MJ, et al. Premature mortality among people with severe mental illness - New evidence from linked primary care data. Schizophr Res [Internet]. 2018 Sep 1 [cited 2019 Mar 27];199:154-62. Available from: https://www.sciencedirect.com/science/article/pii/S0920996418301981?via\%3Dihub

33. Wood S, Marchant A, Allsopp M, Wilkinson K, Bethel J, Jones H, et al. Epidemiology of eating disorders in primary care in children and young people: A Clinical Practice Research Datalink study in England. BMJ Open. 2019 Jul 1;9(8).

34. NCEPOD - Mental Healthcare in Young People and Young Adults (2019) [Internet]. [cited 2020 Jan 22]. Available from: https://www.ncepod.org.uk/2019ypmh.html

35. Brophy S, Kennedy J, Fernandez-Gutierrez F, John A, Potter R, Linehan C, et al. Characteristics of children prescribed antipsychotics: Analysis of routinely collected data. J Child Adolesc Psychopharmacol. 2018 Apr 1;28(3):180-91.

36. Welsh Government: Knowledge and Analytical Services Directorate. Briefing Note Welsh Index of Multiple Deprivation (WIMD) 2014. Briefing Note: Information Research and GIS Team. 2014.

37. Ver Hoef JM, Boveng PL. Quasi-Poisson vs Negative Binomial Regression: How should we model overdispersed count data? Ecology [Internet]. 2007 Nov [cited 2019 Dec 10];88(11):2766-72. Available from: http://doi.wiley.com/10.1890/07-0043.1 
38. Zhang Z, Reinikainen J, Adeleke KA, Pieterse ME, Groothuis-Oudshoorn CGM. Time-varying covariates and coefficients in Cox regression models. Ann TransI Med. 2018 Apr;6(7):121-121.

39. University of Manchester. National Confidential Inquiry into Suicide and Safety in Mental Health [Internet]. 2019 [cited 2020 Feb 10]. Available from: https://www.hqip.org.uk/national-programmes

40. Flensborg-Madsen T, Knop J, Mortensen EL, Becker U, Sher L, Grønbaek M. Alcohol use disorders increase the risk of completed suicide-irrespective of other psychiatric disorders. A longitudinal cohort study. Psychiatry Res [Internet]. 2009 May 15 [cited 2019 Mar 12];167(1-2):123-30. Available from: http://www.ncbi.nlm.nih.gov/pubmed/19359047

41. Aagaard J, Buus N, Wernlund AG, Foldager L, Merinder L. Clinically useful predictors for premature mortality among psychiatric patients visiting a psychiatric emergency room. Int J Soc Psychiatry [Internet]. 2016 Aug 28 [cited 2019 Aug 7];62(5):462-70. Available from: http://www.ncbi.nlm.nih.gov/pubmed/27095414

42. Public Health England. A review of recent trends in mortality in England [Internet]. London; 2018 [cited 2020 Feb 12]. Available from: https://assets.publishing.service.gov.uk/government/uploads/system/uploads/attachment_data/file/827518/Recent_trends_in_mortality_in_England.pdf

43. Gallagher AM, Dedman D, Padmanabhan S, Leufkens HGM, de Vries F. The accuracy of date of death recording in the Clinical Practice Research Datalink GOLD database in England compared with the Office for National Statistics death registrations. Pharmacoepidemiol Drug Saf. 2019 May 1;28(5):563-9.

44. Cheeta S, Drummond C, Oyefeso A, Phillips T, Deluca P, Perryman K, et al. Low identification of alcohol use disorders in general practice in England. Addiction [Internet]. 2008 May 1 [cited 2019 Feb 25];103(5):766-73. Available from: http://doi.wiley.com/10.1111/j.1360-0443.2008.02198.x

45. Davies HR, Nazareth I, Petersen I. Trends of People Using Drugs and Opioid Substitute Treatment Recorded in England and Wales General Practice (19942012). Kuo P-H, editor. PLoS One [Internet]. 2015 Apr 29 [cited 2019 Mar 4];10(4):e0122626. Available from: https://dx.plos.org/10.1371/journal.pone.0122626

46. Frisher M, Martino O, Crome I, Croft P. Trends in drug misuse recorded in primary care in the UK from 1998 to 2005. J Public Health (Oxf) [Internet]. 2009 Mar [cited 2019 Jan 16];31(1):69-73. Available from: http://www.ncbi.nlm.nih.gov/pubmed/18836199

47. Davies-Kershaw H, Petersen I, Nazareth I, Stevenson F. Factors influencing recording of drug misuse in primary care: a qualitative study of GPs in England. Br J Gen Pract [Internet]. 2018 Apr 1 [cited 2019 Feb 27];68(669):e234-44. Available from: http://www.ncbi.nlm.nih.gov/pubmed/29483076

48. Carr MJ, Ashcroft DM, Kontopantelis E, Awenat Y, Cooper J, Chew-Graham C, et al. The epidemiology of self-harm in a UK-wide primary care patient cohort, 2001-2013. 2016 [cited 2019 Nov 20]; Available from: https://clinicalcodes.rss.mhs.man.ac.uk/

49. Marchant A, Turner S, Balbuena L, Peters E, Williams D, Lloyd K, et al. Self-harm presentation across healthcare settings by sex in young people: an ecohort study using routinely collected linked healthcare data in Wales, UK What is already known? Arch Dis Child [Internet]. 2019 [cited 2020 Feb 5];0:1-8. Available from: http://dx.doi.org/10.1136/archdischild-2019-317248

50. Korsgaard HO, Torgersen S, Wentzel-Larsen T, Ulberg R. Substance abuse and personality disorder comorbidity in adolescent outpatients: Are girls more severely ill than boys? Child Adolesc Psychiatry Ment Health [Internet]. 2016 Apr 11 [cited 2020 Feb 11];10(1):8. Available from: http://www.capmh.com/content/10/1/8

51. Biskin RS, Paris J. Diagnosing borderline personality disorder. Vol. 184, CMAJ. Canadian Medical Association; 2012. p. $1789-94$.

\section{Figures}




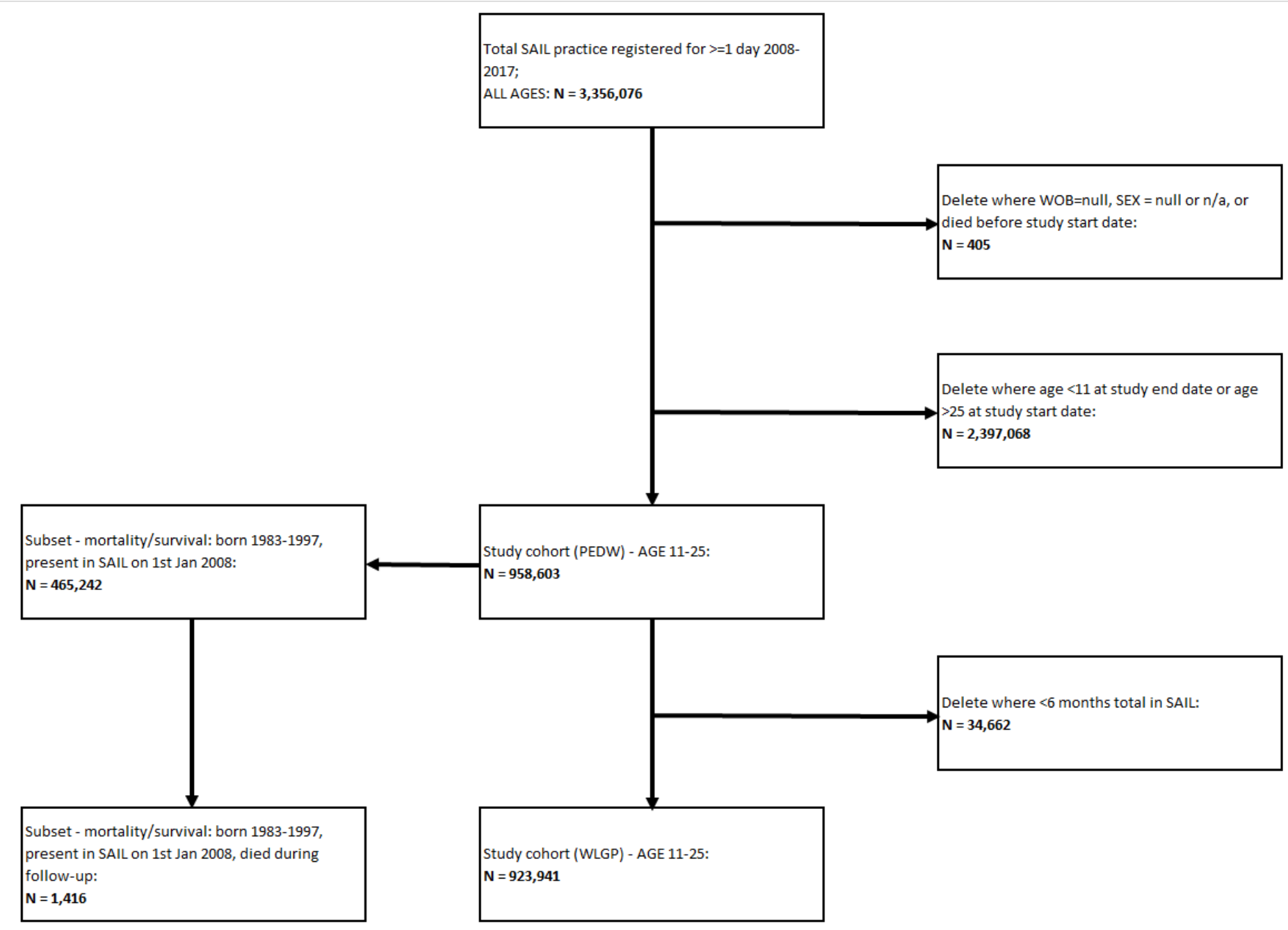

Figure 1

flow diagram of study cohorts 
1st ever incidence rate/1,000 - overall

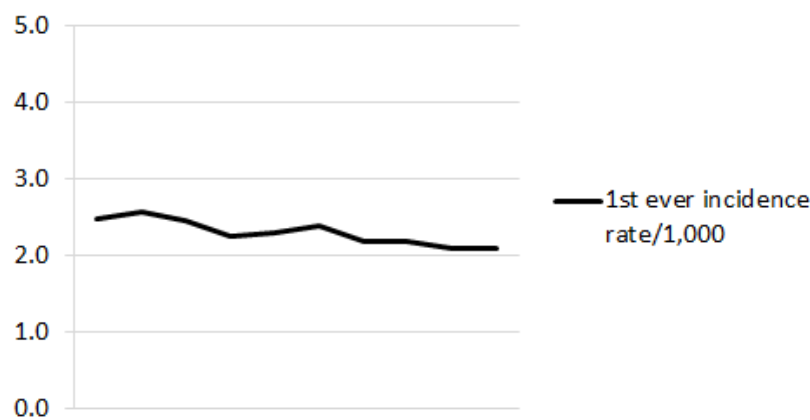

1st ever incidence rate/1,000 - by age band

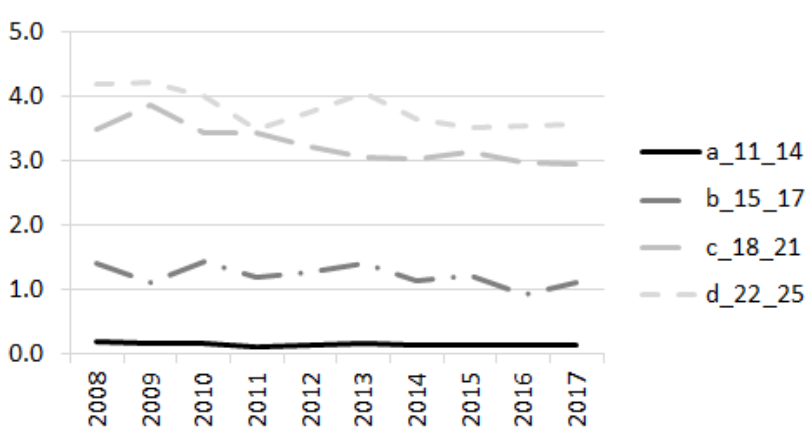

Figure 2

Incidence of CC by year (WLGP)

1st ever incidence rate/1,000 - overall

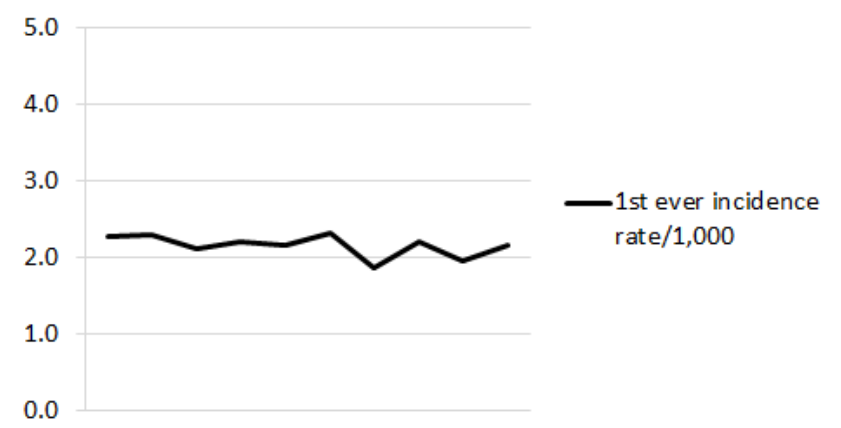

1st ever incidence rate/1,000 - by age band

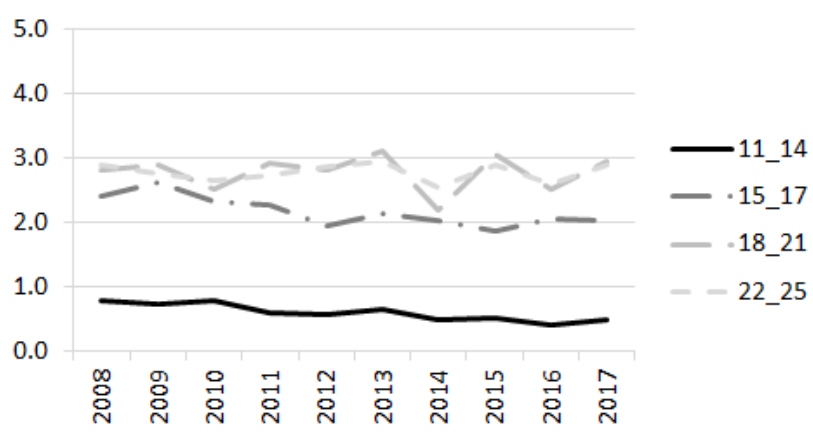

1st ever incidence rate/1,000 - by sex

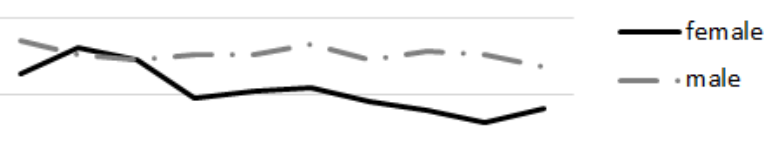

1st ever incidence rate/1,000 - by WIMD quintile

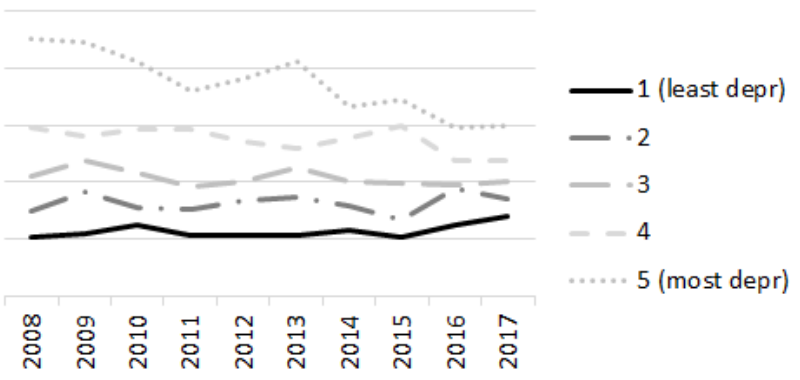

1st ever incidence rate/1,000 - by sex

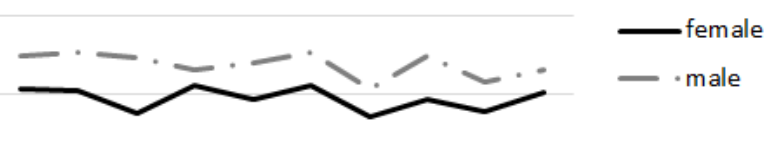

1st ever incidence rate/1,000 - by WIMD quintile

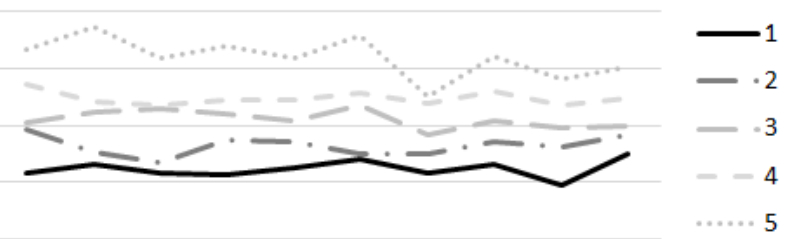

衣

Figure 3

incidence of CC by year (PEDW) 
Deaths per 1000 PYE (95\% Cl) - overall

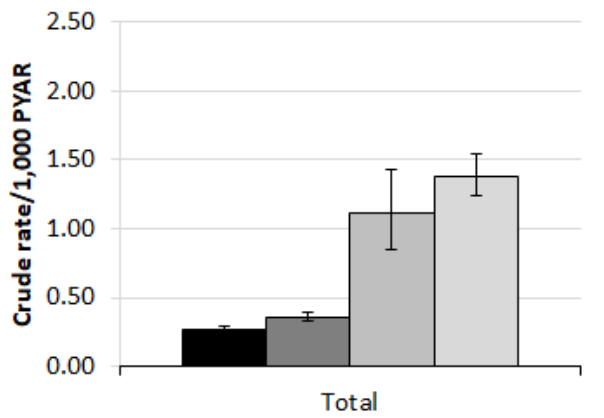

Deaths per 1000 PYE ( $95 \% \mathrm{Cl})$ by sex

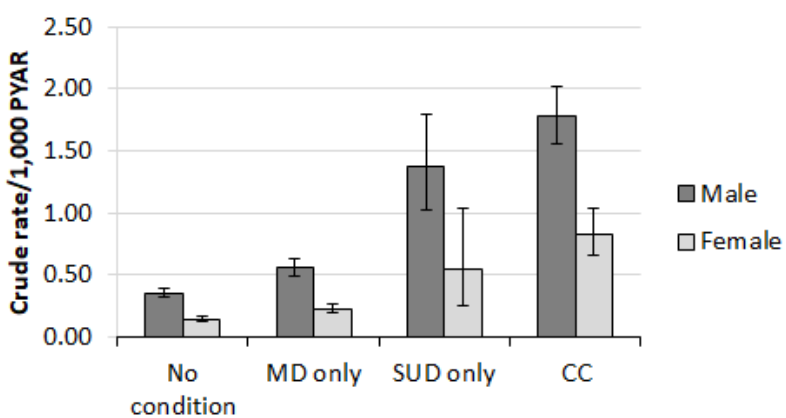

Deaths per 1000 PYE ( $95 \% \mathrm{Cl})$ by age band

- No condition

$\square$ MD only

口SUD only

$\square C C$

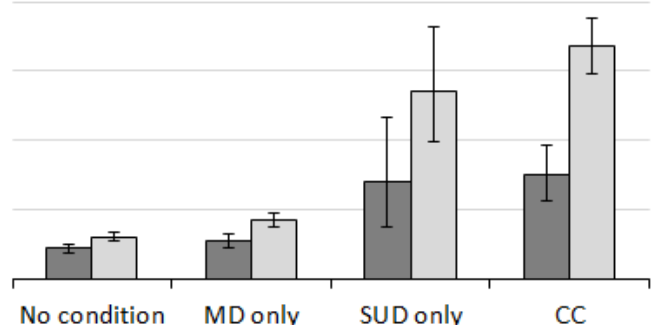

11-17

$\square 18-25$
Deaths per 1000 PYE $(95 \% \mathrm{Cl})$ by WIMD quintile

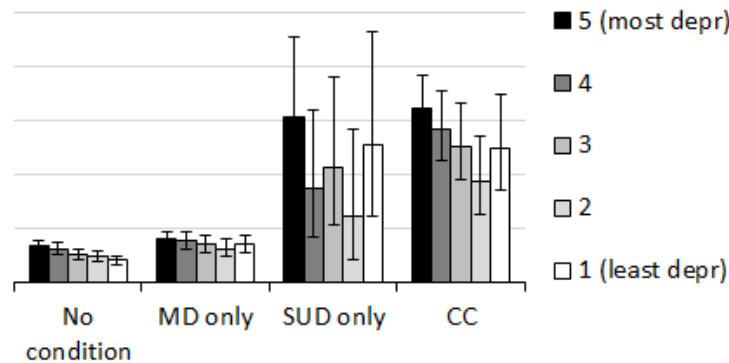

Figure 4

Observed unadjusted mortality rate/1000 PYAR for deaths (all cause) - overall, by sex, age at start of follow-up and WIMD quintile

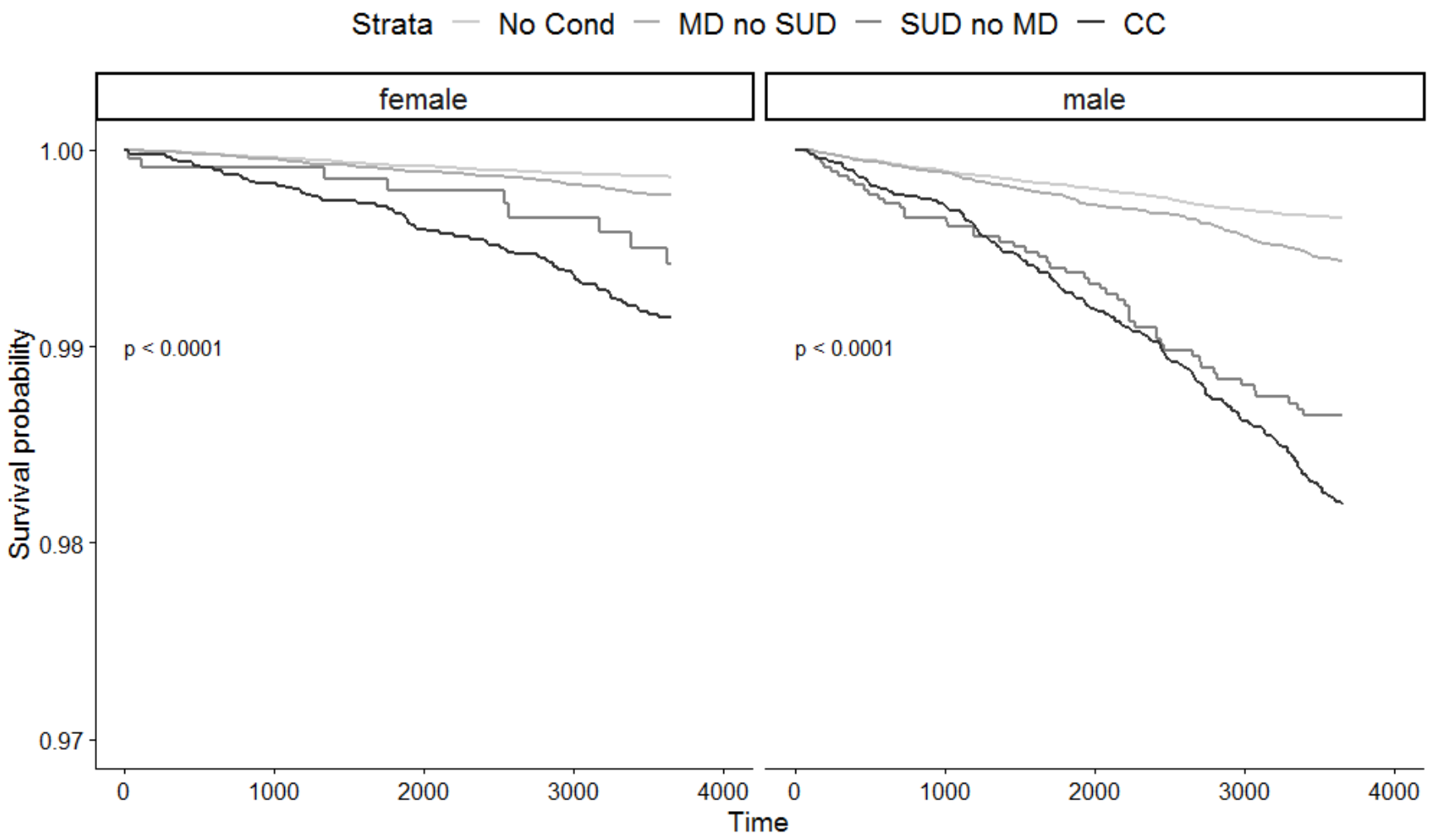

Figure 5

Kaplan Meier survival curve - by sex, stratified by condition group 


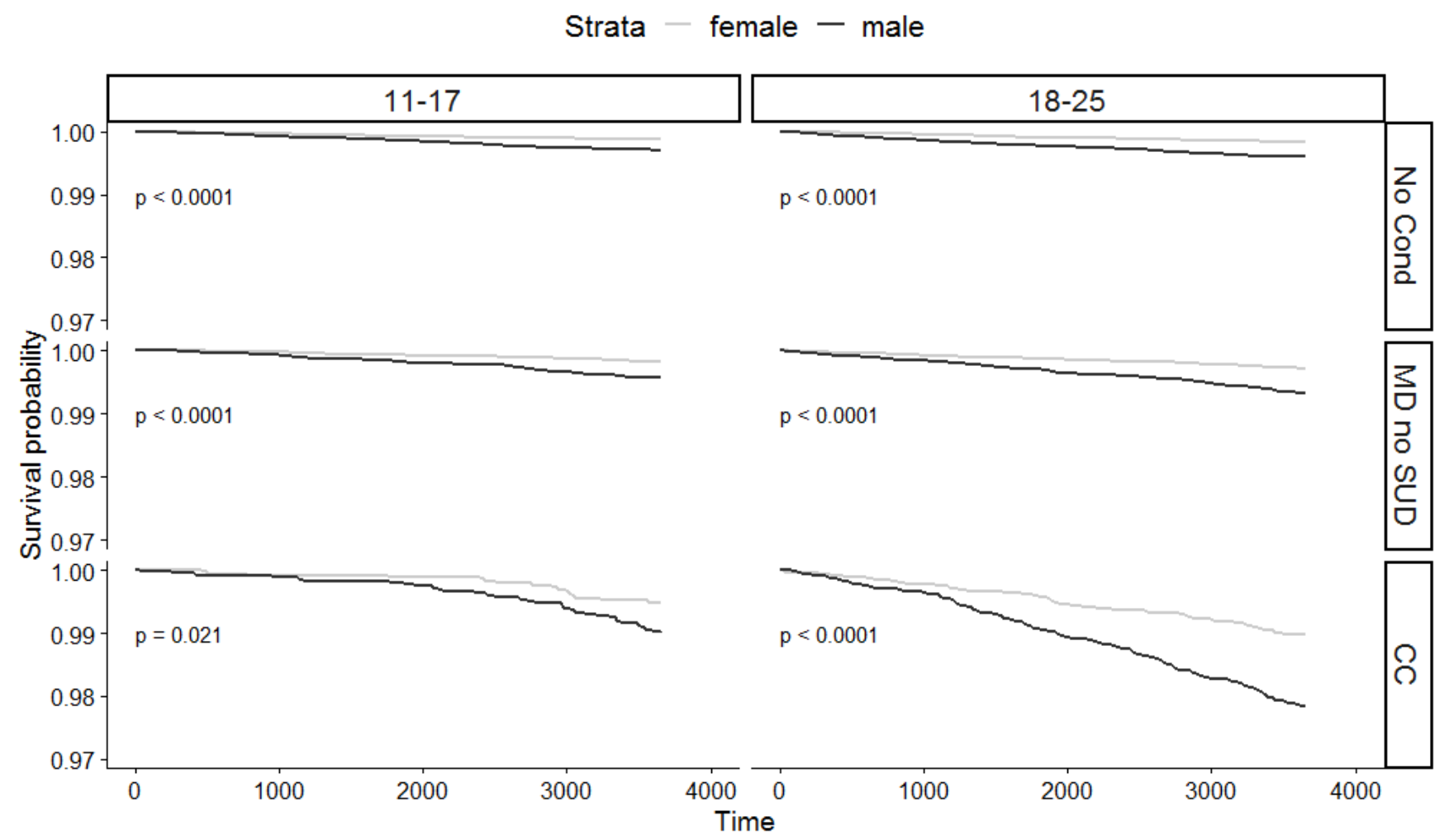

Figure 6

Kaplan Meier survival curve - by age and condition group, stratified by sex

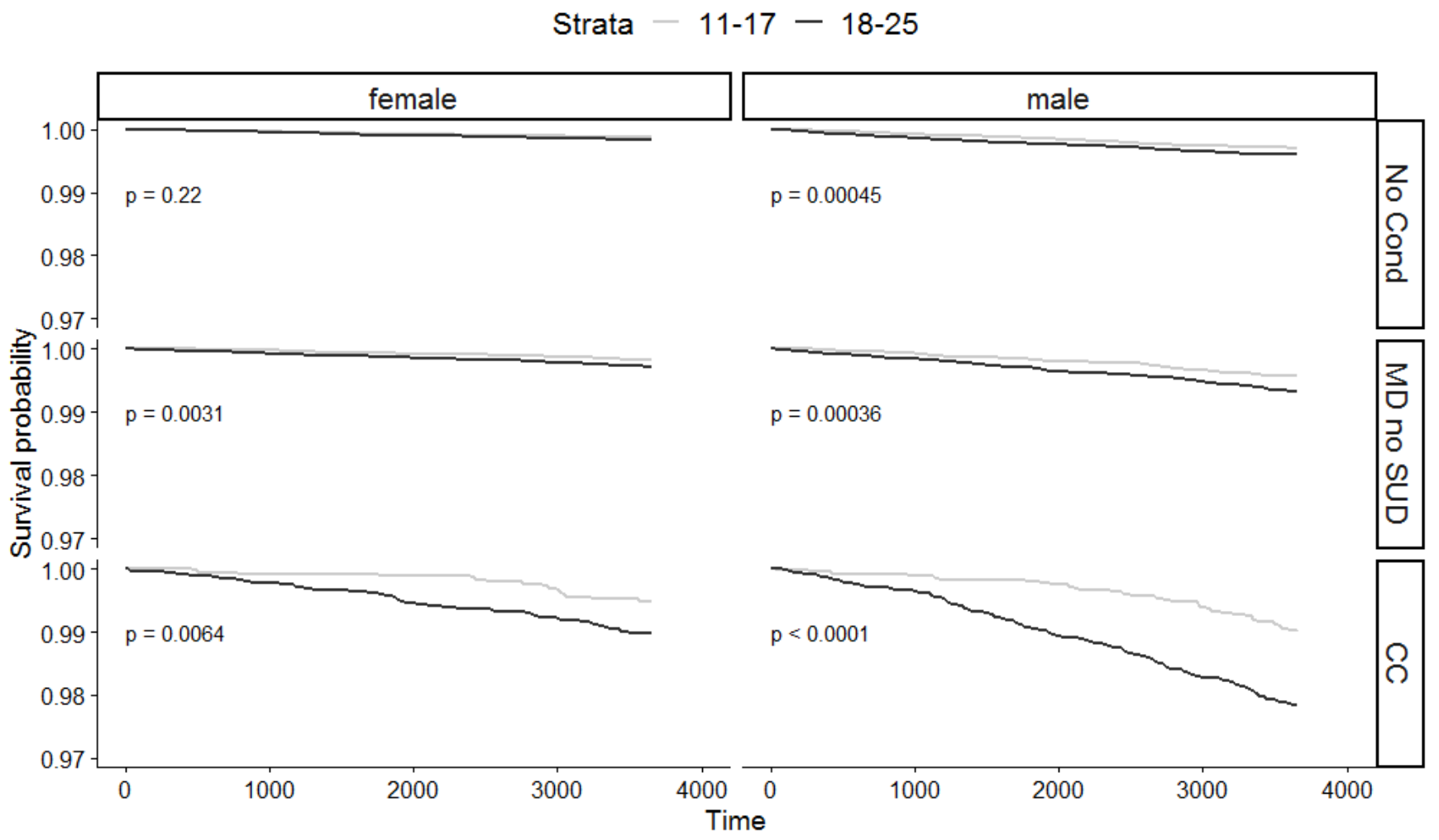

Figure 7

Kaplan Meier survival curve - by sex and condition group, stratified by age 


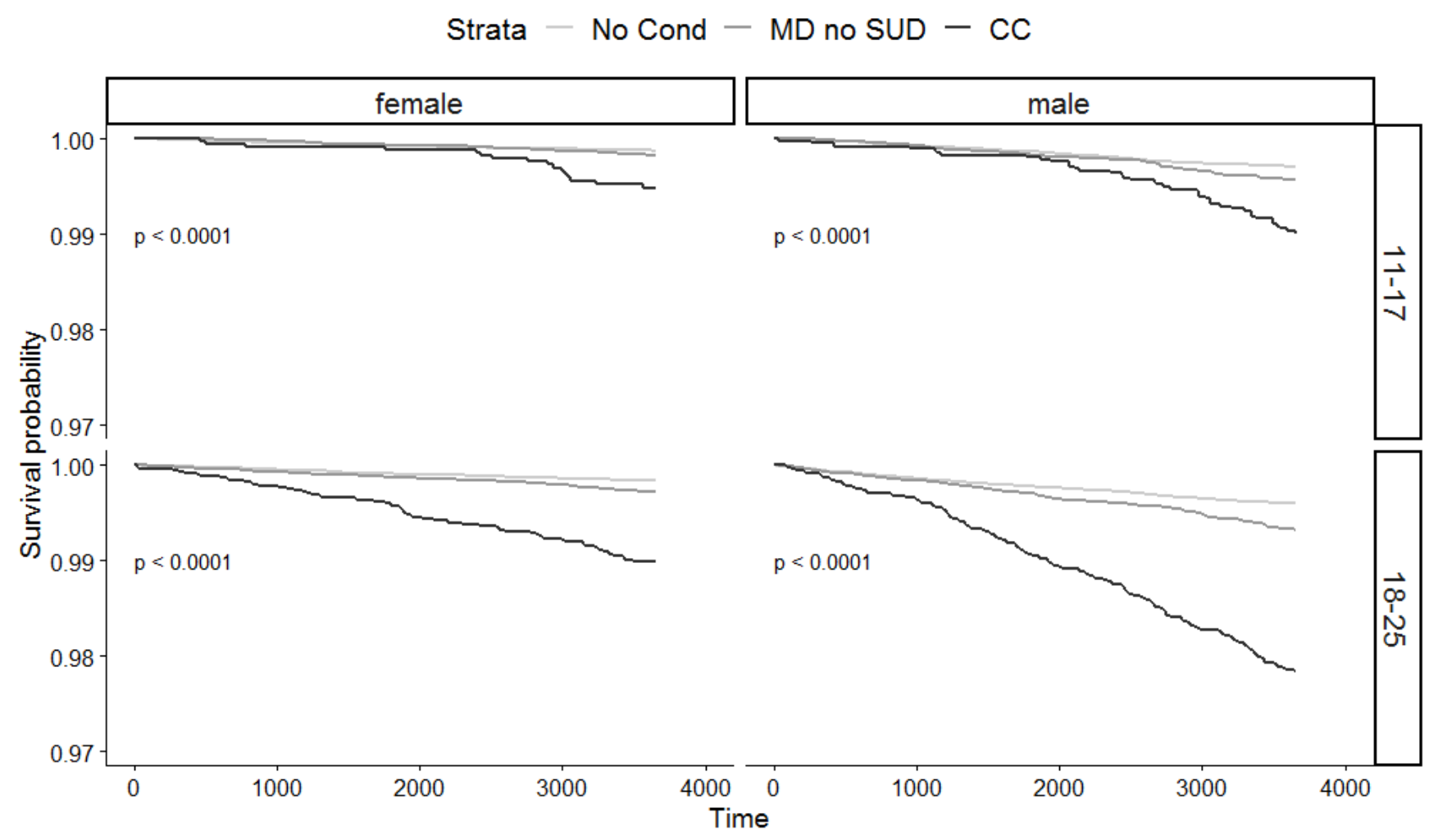

Figure 8

Kaplan Meier survival curve - by sex and age, stratified by condition group

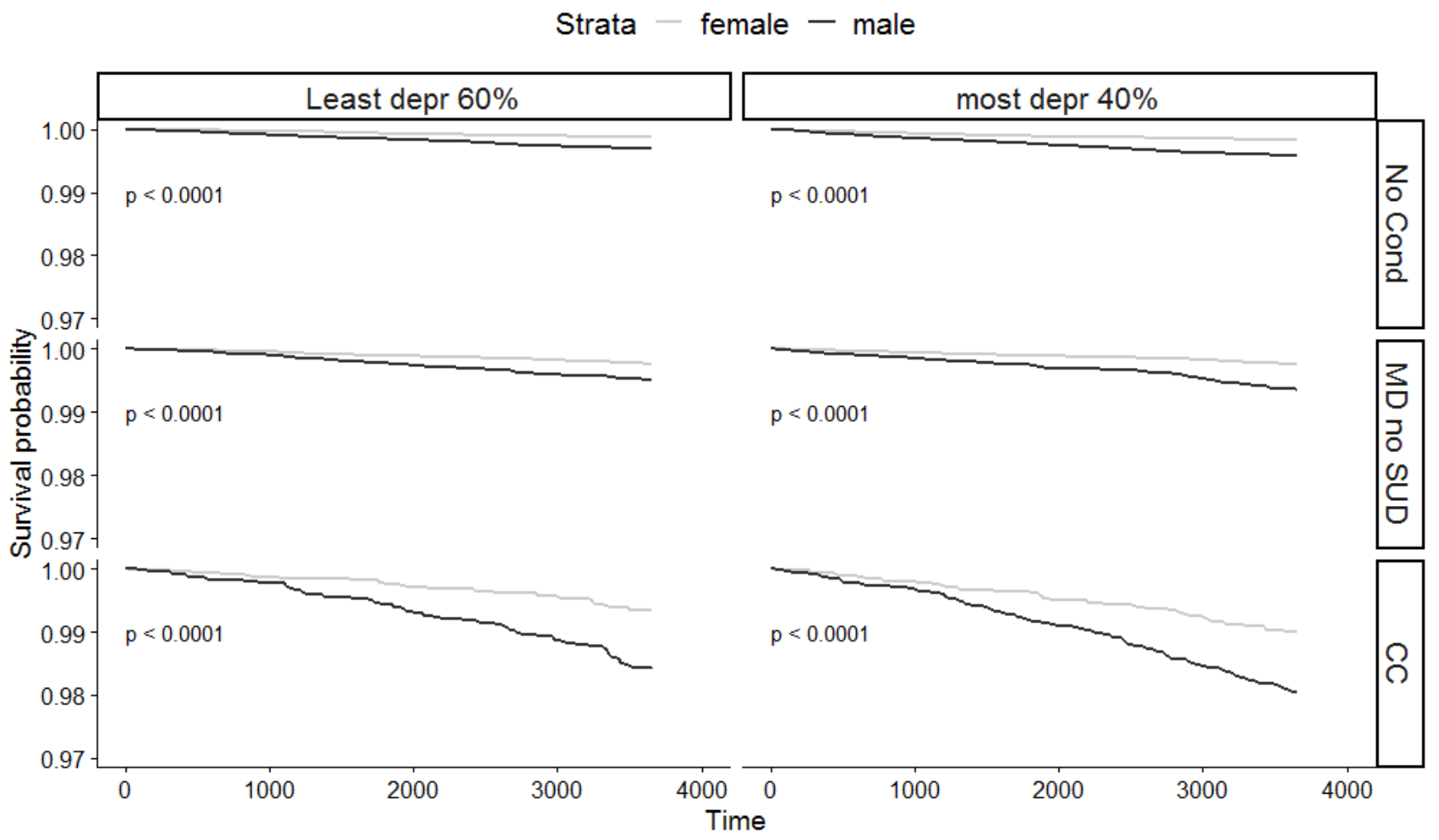

Figure 9

Kaplan Meier survival curve - by WIMD group and condition group, stratified by sex 


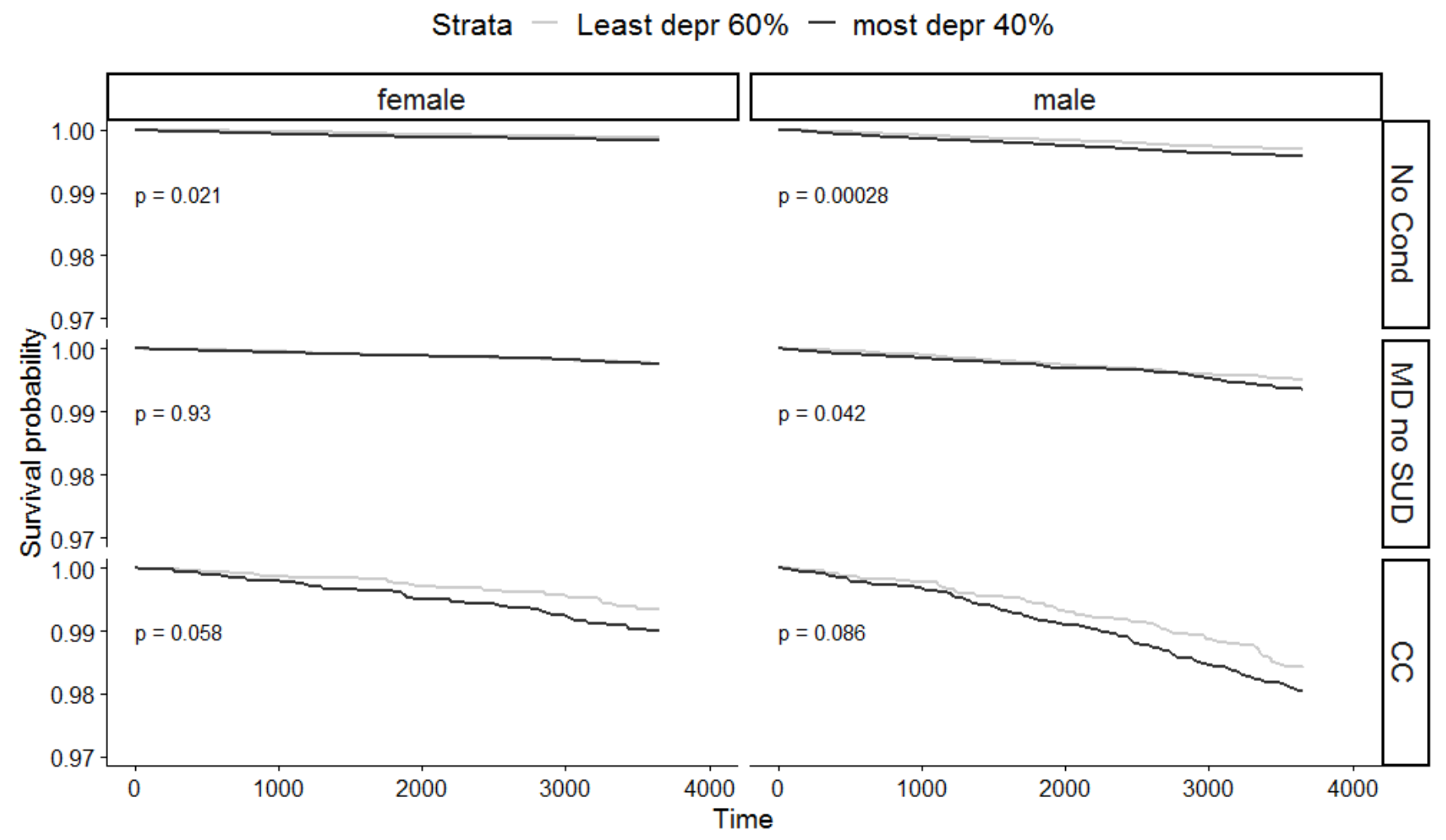

\section{Figure 10}

Kaplan Meier survival curve - by sex and condition group, stratified by WIMD group

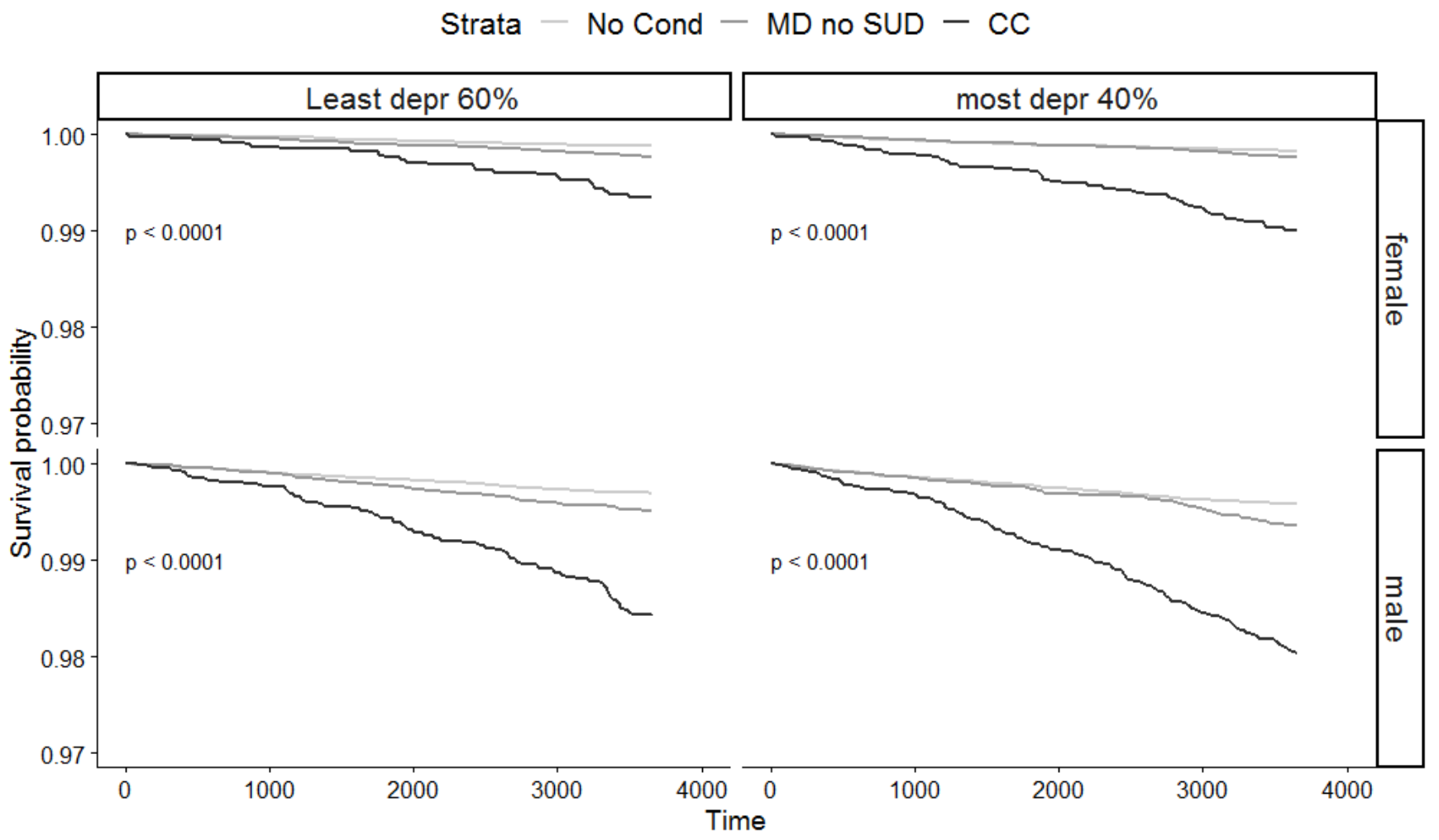

Figure 11

Kaplan Meier survival curve - by WIMD group and sex, stratified by condition group 


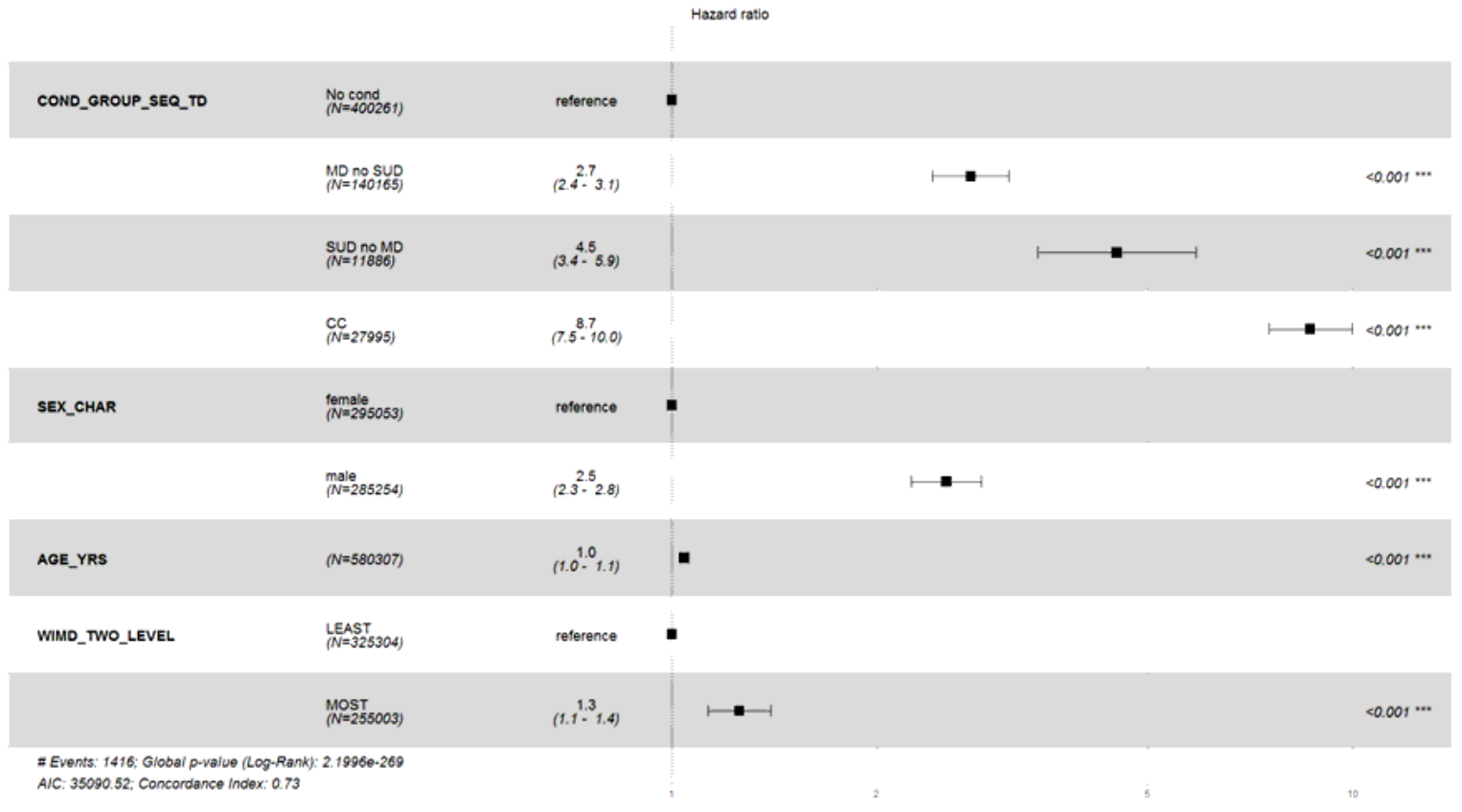

\section{Figure 12}

Cox regression - by condition group, sex, age band at start of follow-up and WIMD group

\section{Supplementary Files}

This is a list of supplementary files associated with this preprint. Click to download.

- Additionalfile1codelists.xlsx 